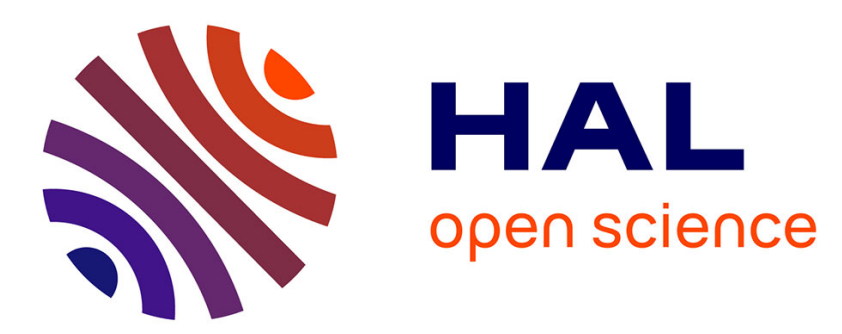

\title{
Upgrading the chemistry of $\pi$-conjugated polymers toward more sustainable materials
}

Lauriane Giraud, Stéphane Grelier, Etienne Grau, Georges Hadziioannou, Cyril Brochon, Henri Cramail, Eric Cloutet

\section{- To cite this version:}

Lauriane Giraud, Stéphane Grelier, Etienne Grau, Georges Hadziioannou, Cyril Brochon, et al.. Upgrading the chemistry of $\pi$-conjugated polymers toward more sustainable materials. Journal of Materials Chemistry C, 2020, 8, pp.9792-9810. 10.1039/D0TC01645D . hal-02872039

\section{HAL Id: hal-02872039 \\ https://hal.science/hal-02872039}

Submitted on 17 Jun 2020

HAL is a multi-disciplinary open access archive for the deposit and dissemination of scientific research documents, whether they are published or not. The documents may come from teaching and research institutions in France or abroad, or from public or private research centers.
L'archive ouverte pluridisciplinaire HAL, est destinée au dépôt et à la diffusion de documents scientifiques de niveau recherche, publiés ou non, émanant des établissements d'enseignement et de recherche français ou étrangers, des laboratoires publics ou privés. 


\section{Upgrading the chemistry of $\pi$-conjugated polymers toward more sustainable materials}

Received 00th January 20xx, Accepted 00th January 20xx DOI: $10.1039 / x 0 x \times 00000 x$

\author{
Lauriane Giraud, ${ }^{a}$ Stéphane Grelier, ${ }^{a}$ Etienne Grau, ${ }^{a}$ Georges Hadziioannou, ${ }^{a}$ Cyril Brochon*a Henri \\ Cramail $^{* a}$ and Eric Cloutet*a
}

\section{Introduction}

There are a lot of concerns today about oil as a limited resource but also because many products arising from petroleum engineering cause severe and somehow irreversible pollution together with the associated negative consequences. Although Chemistry has a 'negative image' for most people, it is important to demonstrate that it can come up with original alternatives in order to build environmental-friendly materials taking into account sustainability and 'greener' processes. This is particularly the case of organic electronics that are ubiquitous in our daily lives and that can take great benefit from the search of alternative synthesis pathways. Indeed, most polymers dedicated to organic electronics (e.g. $\pi$-conjugated polymers) are currently synthesized using transition-metal catalyzed coupling reactions, such as Stille and Suzuki couplings. ${ }^{1,2}$ Despite their efficiency and reliability, these coupling reactions have some issues such as the use of hazardous monomers, toxic solvents, or transition metal catalysts (e.g. $\mathrm{Pd}, \mathrm{Ni}, \mathrm{Fe}$, etc.) that end up as residual impurities in final devices, thus acting as failure agents. ${ }^{3}$ While efforts have been made to reduce metal impurities or to use less toxic solvents there is room for improvement. ${ }^{4}$ Herein, we will notably report on 'Direct Heteroarylation Polymerization (DHAP)' enabling the use of less hazardous monomers, but also on coupling reactions involving less or no transition-metal catalysts. In a second part of this manuscript we would like to enter in a new era where $\pi$ conjugated polymers could be made from bio-sourced monomers. Indeed, an alternative to petroleum resources is biomass. Biomass is a "Material produced by the growth of micro-organisms, plants or animals" ${ }^{\prime \prime}$. Therefore, there is not "one" biomass, but rather multiple biomasses, each with its own characteristics. One promising biomass is the lignocellulose: the latter has a rather short production cycle (from 1 to 50 years) and does not compete with food production, as opposed to crop biomass, for example. Lignocellulosic biomass can be used for energy production and has the potential to provide a large palette of molecules that can enter the game. $6,7,8$

\section{Synthesis of $\pi$-conjugated polymers via more sustainable pathways}

\subsection{Direct Heteroarylation Polymerization}

Despite their reliability and efficiency, common methodologies used to synthesize $\pi$-conjugated polymers have several drawbacks. One of them is the use of hazardous monomers and subsequently the production of hazardous by-products, as discussed in the introduction. For instance, the Stille reaction requires trialkylstannane monomers and leads to the production of stoichiometric amounts of tin-based by-products. ${ }^{2}$ Direct Hetero Arylation Polymerization, or DHAP, is a relatively recent method that enables the synthesis of $\pi$-conjugated polymers while generating fewer wastes and using "simpler" and less hazardous monomers. ${ }^{9}$ Indeed, DHAP is a metal-catalyzed coupling reaction between an arene and an aryl halide (see Scheme 1). 


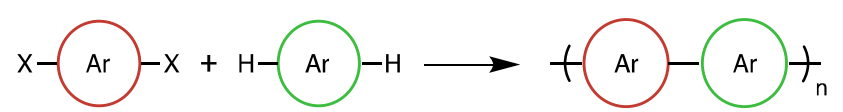

Scheme 1: General reaction scheme of DHAP ( $\mathrm{X}=$ halogen)

DHAP was first investigated by Lemaire and coll. to synthesize poly(alkylthiophenes). ${ }^{10}$ This reaction has since then been used to synthesize various $\pi$-conjugated polymers. Indeed, DHAP has multiple advantages, the main one being that it is done on easily accessible monomers: arene and aryl halide. DHAP also allows the use of monomers bearing various substituents. ${ }^{11}$ The latter coupling reaction is performed with a metal-based catalyst such as rhodium (III/IV) or palladium-based catalysts that are more frequently investigated. Palladium acetate is the most employed, as it was reported to improve deprotonation of the arene. ${ }^{12}$ Two other reagents are used to perform DHAP: a Brönsted base which neutralizes the hydrogen halides formed during the reaction and a phosphine ligand. The latter's role is still investigated, and the phosphine ligand is chosen on a case-by-case basis. Some phosphinefree systems were reported to reduce the amount of impurities in the final polymers. ${ }^{13,14}$ Despite its various applications and promising results, DHAP also has issues originated from the catalytic system used. Indeed, the latter leads to the formation of impurities in the final polymers, affecting their properties. ${ }^{3}$ DHAP also has the disadvantages of not controlling the regioselectivity and of enabling homo-coupling which can induce structural defects in the final polymers leading to poor opto-electronic performance. Homocoupling can be avoided by a careful choice of experimental conditions, such as the use of the proper phosphine ligand or relatively low temperature. ${ }^{15}$ The lack of regioselectivity and branching reactions can be avoided by tuning the experimental conditions (choice of solvent and catalyst), and also by blocking the other positions. Kanbara and coll. investigated the latter strategy, as represented in Scheme 2. DHAP allows the synthesis of polymers that cannot or can hardly be synthesized by "traditional" coupling. DHAP also enables to synthesize polymers with similar or even better properties than polymers synthesized with Stille or Suzuki couplings for example. For instance, Kanbara et al. synthesized a polymer through various experimental protocols, as summed up in Figure 1.

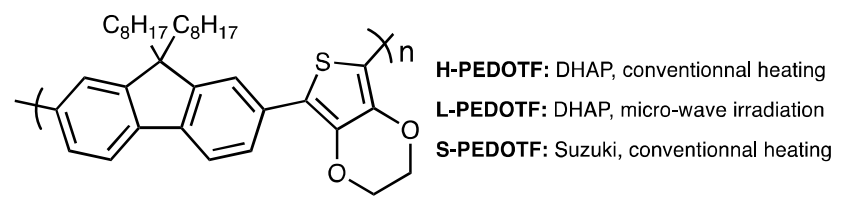

Figure 1: Structure of PEDOTF, synthesized via various ways: DHAP and Suzuki coupling 16
DHAP using conventional heating yielded the highest average molar mass values $(147000 \mathrm{~g} / \mathrm{mol})$ with a dispersity around 3 (H-PEDOTF). Comparatively, S-PEDOTF (obtained by Suzuki coupling) has a $M_{n}$ value of $47500 \mathrm{~g} / \mathrm{mol}$ and a lower dispersity (2). The authors investigated the remaining quantities of palladium in the final polymers: this value is 1590 and 2300 ppm for H-PEDOTF and LPEDOTF respectively and $4390 \mathrm{ppm}$ for S-PEDOTF. This doubled value for S-PEDOTF can be explained by a higher quantity of catalyst required for Suzuki coupling $(5 \% \mathrm{~mol}$, opposed to $1 \% \mathrm{~mol}$ for the DHAP). The aforementioned polymers were then integrated in OFET and photovoltaic devices: in both cases, H-PEDOTF gave the best results. Indeed, the H-PEDOTF OFET exhibited a field-effect hole mobility of $1.2 \pm 0.1 \times 10^{-3} \mathrm{~cm}^{2} \mathrm{~V}^{-1} \mathrm{~s}^{-1}$, and the H-PEDOTF-based photovoltaic device a PCE of $4.08 \%$, whereas S-PEDOTF-based led to a mobility of $3.2 \pm 0.2 \times 10^{-5} \mathrm{c} \mathrm{m}^{2} \mathrm{~V}^{-1} \mathrm{~s}^{-1}$, and PCE of 0.48 . According to the authors, the high molar masses and good purity of H-PEDOTF explained the improved properties of the OFET and solar cells. ${ }^{16}$ Kanbara's team has extensively worked on DHAP, aiming at testing new monomers or experimental conditions (e.g. use of micro-wave reaction to reduce reaction time ${ }^{16}$ ). Leclerc and coll. have also worked extensively on DHAP. 17,18,19 The authors notably synthesized a polymer by DHAP in batch but also following continuous flow process, which would lower the price of the synthesis - the reaction scheme is given in Scheme 3. The obtained polymer has a $M_{n}$ value around $30000 \mathrm{~g} / \mathrm{mol}$, and the synthesis is quite reproducible however the dispersity is rather high under continuous flow ( 2 in batch, but $\sim 3$ under continuous flow). The isoindigo-based polymer obtained has promising properties for OFET and solar cells, as the authors integrated it in devices with PCE up to $3 \%$ with a polymer synthesized in batch, and $1.80 \%$ for a polymer obtained under continuous flow. This lower value can be explained by the polymer's lower molar mass. (NB: isoindigo, while being an isomer of indigo, is not bio-based ${ }^{20}$ ).

\subsection{One step further: transition-metal free syntheses}

Usluer et al. showed that poly(3-hexylthiophène)'s properties were greatly improved after removing metal traces. ${ }^{3}$ Indeed, the latter act as charge traps and extensive purification is needed to remove them. The best OFET and OPV performances were obtained for a polymer purified with a Soxhlet apparatus and metal complexing agents. The latter purification techniques require time, energy and solvents. Kanbara and coll. investigated the role of terminal halogen atoms on polymers' properties and concluded that the presence of terminal bromide had a bigger impact on opto-electronic properties than residual palladium. ${ }^{21}$ Indeed, even though they can affect the final optoelectronic properties (especially for low molar mass polymers), few studies have deeply investigated the nature of chain termini of $\pi$-conjugated polymers. Thus, limiting the use of not only transition metals but also halogens is crucial, to avoid long and tedious purification but also additional steps to remove the final halogen, and improve the polymers' properties. The next section first lists reactions leading to $\pi$-conjugated polymers without the use of transition metals but with halogen atoms. Then, reactions with 
neither halogen atoms nor transition metals are exemplified. The aim of this section is not only to provide an exhaustive list of transitionmetal free syntheses, but rather to identify key reactions leading to promising polymers for organic electronic applications and/or reactions that could be applied to bio-based monomers (the latter being studied in part 3 of this manuscript).

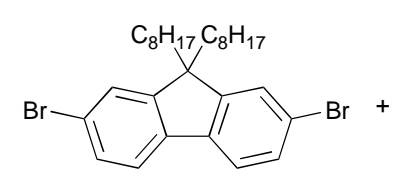<smiles>Fc1cc(F)c(F)cc1F</smiles>

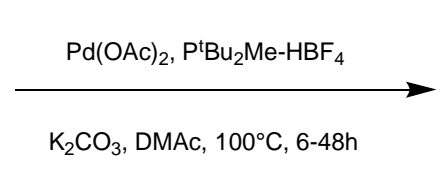<smiles>[13CH2]C1([14CH2])c2cc(I)ccc2-c2ccc(-c3c(F)c(F)c(F)c(F)c3F)cc21</smiles>

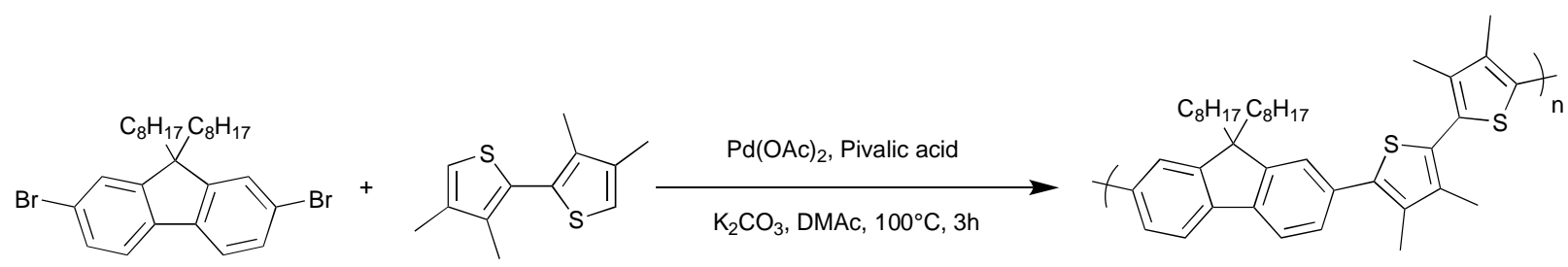

Scheme 2: Synthesis of polymers via DHAP using monomers with blocked positions (Top: adapted with permission from Ref ${ }^{22}$. Copyright $\subset$ 2011 American Chemical Society. Bottom: adapted with permission from Ref ${ }^{14}$. Copyright (C2012 American Chemical Society)

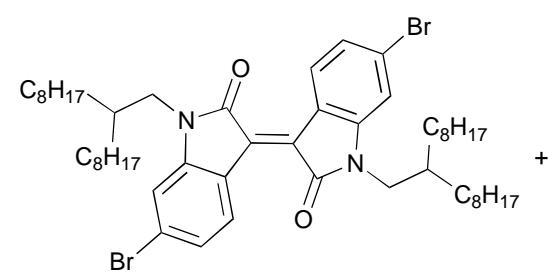<smiles>c1scc2c1OCCO2</smiles>

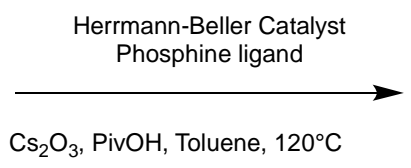

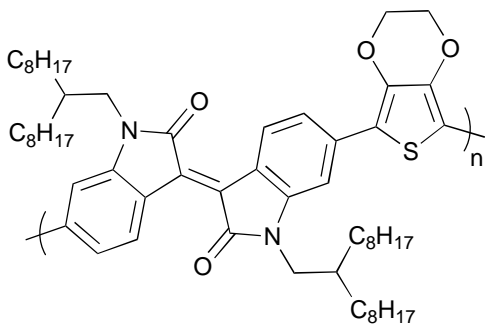

Scheme 3: Synthesis of PiEDOT by DHAP (Adapted with permission from Ref. ${ }^{23}$. Copyright (C2015 American Chemical Society)

\subsection{1. $\pi$-Conjugated polymers synthesized with halogen \\ 2.2.1.1. Bromine-catalyzed reaction}

Patra et al. investigated the synthesis of PEDOT and PEDOS using bromine as a catalyst, as it is represented in Scheme 4.

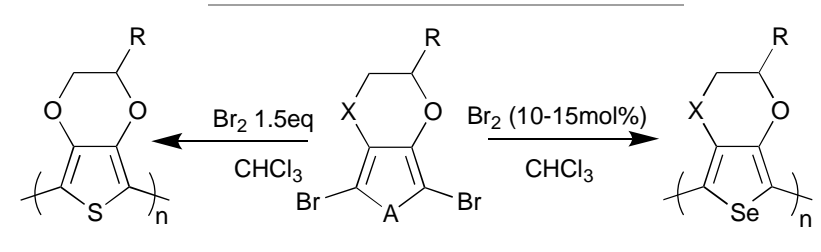

$\mathrm{X}=\mathrm{S}$ or $\mathrm{O}$

Scheme 4: Synthesis of PEDOT (left) and PEDOS (right) derivatives (adapted with permission from Ref ${ }^{24}$. Copyright @2015 American Chemical Society)

The authors hypothesized that the polymerization starts with the oxidation of the monomers by $\mathrm{Br}_{2}$ to form a radical cation. The latter then attacks the monomer, resulting in the formation of a dimer and elimination of bromine. The dimer species is more reactive than the monomer and subsequently reacts with the latter, leading to the polymer growth. This process works well to synthesize PEDOS, a type of polymer hardly synthesized by other methods. Yet these experimental conditions are poorly adapted to the synthesis of PEDOT, even with an excess of bromine. Indeed, neither soluble PEDOT nor PEDOT's analogues were obtained using the brominecatalyzed coupling. Moreover, the insoluble recovered polymer had a low conductivity. However, this coupling is well-adapted for the synthesis of PEDOS, yielding polymers with $M_{n}$ values of $4000-5000$ $\mathrm{g} / \mathrm{mol}$ with dispersity of $2.1-2.3$, and promising properties for applications as hole transport layers. ${ }^{24}$ Nevertheless the authors do not comment on the regioregularity of the obtained PEDOS. Heeney et al. reported the synthesis of regioregular PEDOS but using a transition metal catalyzed coupling. ${ }^{25}$ To remove the remaining bromine at the end of the reaction, Patra and coll. reported the use of hydrazine hydrate and extraction with a Soxhlet system to "dedope" the polymers after synthesis; a rather long and tedious 
purification - the authors also did not comment on the amount of bromine left after purification.

\subsubsection{Synthesis of $\pi$-conjugated polymers by oxidative homo-} coupling of bis-Grignard reagents

A Nitroxide-Mediated Radical Polymerization (NMRP) approach was successfully applied to the synthesis of $\pi$-conjugated polymers. This homo-coupling of Grignard reagents does not require any transition metal, but halogen, magnesium and lithium-bearing species are needed to perform this polymerization. The use of the latter metals is also questionable as possible residual metal impurities in final polymers which will not be discussed in this manuscript. Studer et al. investigated the synthesis of polyfluorene using this approach, with TEMPO as a catalyst (Scheme 5). ${ }^{26}$ The latter can be regenerated after treatment with air, which is interesting both from economical and sustainable points. Polyfluorene was obtained in good yield (more than 90\%) with average molar mass lower than the ones obtained by GRIM synthesis ( $9000 \mathrm{~g} / \mathrm{mol}$ vs $62000 \mathrm{~g} / \mathrm{mol}$ ) but higher dispersity (2.0-2.2 vs 1.5). ${ }^{27}$ The homo-coupling of Grignard reagents also leads to fewer residual transition metals in the final impurities: 1-15 ppm of nickel were detected in polyfluorene synthesized through this method, compared to $840-1560 \mathrm{ppm}$ for a polyfluorene synthesized with GRIM polymerization. Studer and coll. also investigated the synthesis of other fluorene-based $\pi$-conjugated polymers using the NMRP approach, as represented in Figure $\mathbf{2}$.

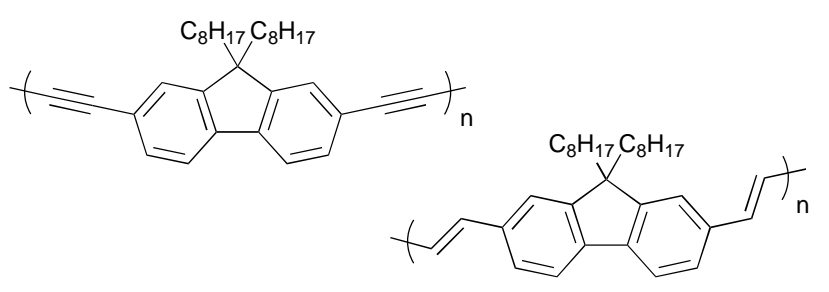

Figure 2: Structure of fluorene-based polymers obtained by oxidative homo-coupling of Grignard reagent 26

The fluorene-based polyvinylene could be integrated in OLED for example, as it has a strong fluorescence (quantum yield of 0.5 ). ${ }^{28}$ However, the oxidative homocoupling of Grignard reagent has also some drawbacks such as the presence of bromine atoms at chain ends affecting the final features. In addition, the synthesis of the bisGrignard monomer is long and tedious. Indeed, the latter has to be obtained with high purity in order to make sure of the good progress of the polymerization afterwards. ${ }^{26}$

2.2.2. Synthesis of $\pi$-conjugated polymers without halogen via condensation reaction

2.2.2.1. Synthesis of polyazomethines
Polyazomethines have been widely investigated, as they have multiple applications for opto-electronics. ${ }^{29,30,31}$ Their main advantage is their easy synthesis and recovery as they can be obtained from the condensation of a diamine and a dialdehyde, without any catalyst, releasing water as by-product. This straightforward method enables the formation of polymers without extensive purification. Subsequently a wide range of polymers can be obtained, with various properties by changing the monomers. ${ }^{32,33}$ Polyazomethines may exhibit some stability issues which is not true in the case of poly(arene imine)s. Skene and coll. investigated extensively the synthesis of fluorene-based polyazomethines; the authors successfully synthesized all fluorene-based polyazomethines, as represented in Figure $\mathbf{3}$. The polyazomethine noted $\mathbf{1}$ has promising properties, such as fluorescence (quantum yield (QY) at 0.19 ) and electrochromism. High $M_{n}$ values could be obtained, up to $145800 \mathrm{~g} / \mathrm{mol}$ after few days of polymerization (performed in a pressure tube). ${ }^{34}$ Polyazomethine $\mathbf{2}$ was obtained by self-condensation of a monomer bearing both amine and aldehyde functions. However, the reaction required additional metallic catalyst $\left(\mathrm{TiCl}_{4}\right)$. Additionally, the $\mathrm{M}_{\mathrm{n}}$ value is low: only $2180 \mathrm{~g} / \mathrm{mol}$ after one week of reaction. Yet this polyazomethine has promising properties, as it is highly fluorescent ( $Q Y$ of 0.48 ); the authors also investigated its use as detector for explosive. ${ }^{35}$

\subsubsection{Knoevenagel reaction}

The Knoevenagel reaction can yield $\pi$-conjugated polymers bearing a pendant cyano group. The latter can improve electron affinity, therefore leading to specific properties to the final materials. Greenham et al. investigated the synthesis of a PPV-like polymer, as represented in Scheme 6. The polymer obtained was successfully integrated into OLED showing promising properties. ${ }^{36}$ However, the Knoevenagel reaction does not allow a good control of the final polymer's regioselectivity, leading to structural defect with adverse effects on opto-electronic properties. ${ }^{37}$ Another type of PPV-like polymer was obtained by Knoevenagel reaction by Cao et al. as represented in Scheme 7. 
Journal Name
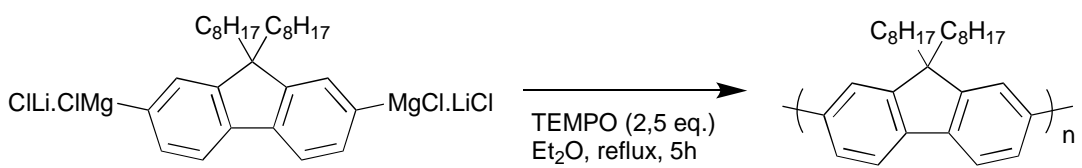

Scheme 5: Synthesis of polyfluorene by oxidative homo-coupling of Grignard reagent (adapted from Ref. ${ }^{26}$ with permission of John Wiley and Sons, Inc.)

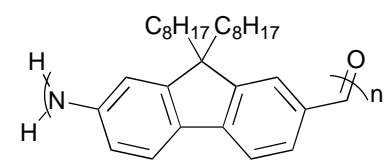

1

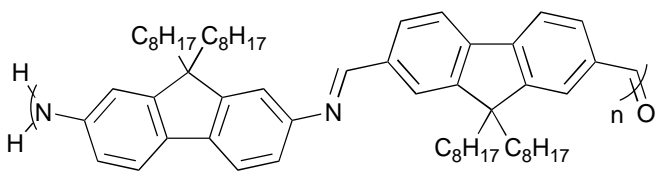

2

Figure 3: Fluorene-based polyazomethines 34,35

The polymer obtained showed promising applications for hydrogen production, but low quantum yield (0.03). This could be due to selfquenching, a phenomenon frequently reported for aggregates. ${ }^{38}$ Moreover, the polymer is poorly soluble, which makes it harder to process. $^{39}$

\subsubsection{Horner-Wadsworth-Emmons reaction}

The Horner-Wadsworth-Emmons (HWE) reaction is an alternative to the Wittig reaction and enables well-controlled polymerization. Indeed, the HWE reaction allows for a better control of regioselectivity, as it leads primarily to double bonds with trans configuration - this is not the case for the Wittig reaction, which also leads to cis configuration. The general scheme of the HWE reaction is given in Scheme 8. Liao and coll. synthesized various polymers and model compound mimicking their backbone using the HWE reaction (Figure 4). Only the polymer bearing an n-hexyl group was characterized by SEC and NMR, suggesting that the others were not soluble in common solvents. The latter soluble polymer has a $M_{n}$ value of $4000 \mathrm{~g} / \mathrm{mol}$, and a dispersity of 2.1 . All polymers showed intense fluorescence ( $Q Y$ from 0.4 to 0.55 ), while the corresponding model compound has a quantum yield of $0.68 .{ }^{40}$ This increased quantum yield is most likely due to self-quenching of the polymers, a phenomenon that does not affect the smaller model compound. ${ }^{38}$ The polymers were integrated in OLEDs emitting in the blue range. Van de Wetering and coll. used the HWE reaction to synthesize poly(thienylenevinylene). The latter corresponded to one block of a low bandgap polymer, with the objective of using the latter for photovoltaic application. ${ }^{41}$

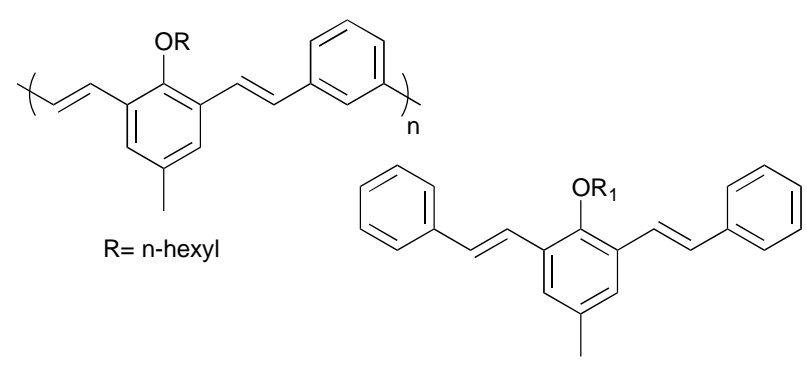

$\mathrm{R} 1=$ n-butyl, n-hexyl, n-octyl

Figure 4: Polymer and model compound mimicking its backbone, all synthesized with HWE reaction ${ }^{40,42}$

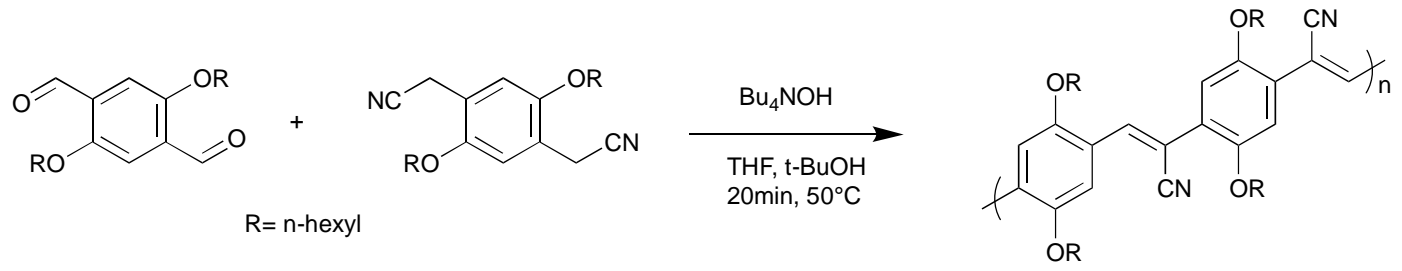

Scheme 6: Synthesis of $\pi$-conjugated polymer via Knoevenagel reaction (Adapted from ${ }^{36}$ ) 


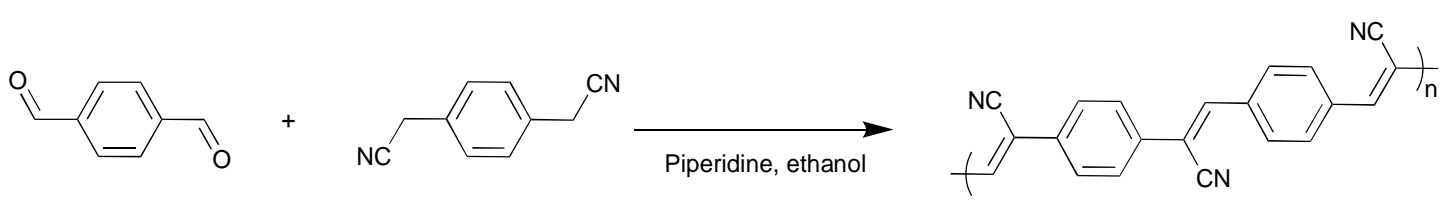

Scheme 7: Synthesis of PPV like polymer via Knoevenagel reaction (Reproduced from Ref. ${ }^{39}$ with permission from The Royal Society of Chemistry)

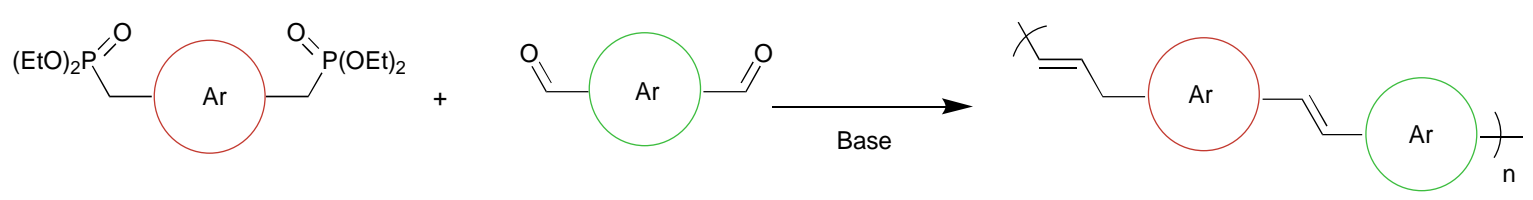

Scheme 8: General scheme of the Horner-Wadsworth-Emmons reaction

The HWE reaction was also used on a monomer bearing both an aldehyde function and a phosphonic acid function. Yet the authors tried to avoid self-condensation to control the polymerization and achieve chain-growth polymerization (Scheme 9). Crown ethers were used to capture the potassium cation, leading to higher $M_{n}$ values: up to $7600 \mathrm{~g} / \mathrm{mol}$, with a dispersity of 1.2 . When targeting $M_{n}$ values higher than $10000 \mathrm{~g} / \mathrm{mol}$, precipitation was observed, most likely due to strong $\pi-\pi$ interactions leading to aggregations, as suggested by the authors. ${ }^{43}$ The main drawback of the HWE reaction is the production of phosphorus-based wastes.

\subsubsection{Condensation of squaric acid}

Polysquaraines are characterized by a low band gap and absorption in the near infrared range. The latter can be obtained by reacting squaric acid and an electron rich moiety, ${ }^{44}$ which can be aromatic or heterocyclic, as represented in Scheme 10. The polymer obtained in Scheme 10 was successfully integrated in OFET with promising properties $\left(5 \times 10^{-4} \mathrm{~cm}^{2} \mathrm{~V}^{-1} \mathrm{~s}^{-1}\right.$ with an unoptimized device) and in solar cells with high power conversion efficiency (0.86\%). ${ }^{45}$ The polysquaraines represented in Figure 5 were synthesized by
Stille/Suzuki coupling and by condensation of squaric acid. Interestingly, the metal-free approach led to higher $M_{n}$ values. These two polysquaraines exhibited a low band gap (1.6-1.7 eV) and promising properties for their future integration in bulk heterojunction solar cells. ${ }^{46}$ By changing the comonomer, various polysquaraines can be obtained, as illustrated in Figure 6. The polymer $\mathbf{3}$ was used as a sensor for humidity for breath monitoring, with short response time (less than a second). The latter polymer is most likely poorly soluble and was used to decorate silver particules. ${ }^{47}$ On the contrary the polymer $\mathbf{4}$ is water-soluble, a promising property for bio-imaging. ${ }^{48}$ Various derivatives of the polymer $\mathbf{5}$ were synthesized, as solvent (1,3-propane diol) can be integrated in the polymer chains, allowing to tune the optical properties. This type of polymer was integrated in OLED giving promising properties (almost white emission). However, such polymers show quite low $M_{n}$ values (e.g. $3700 \mathrm{~g} / \mathrm{mol}$ at most) and absorbance in the visible range. In addition, polysquaraines were also obtained after chlorination of the squaric acid monomer through the alcohol functions in order to evidence the ratio of 1,3 vs 1,2 squaraine subunits' linkages. ${ }^{49}$ 
Please do not adjust margins

Journal Name

Article
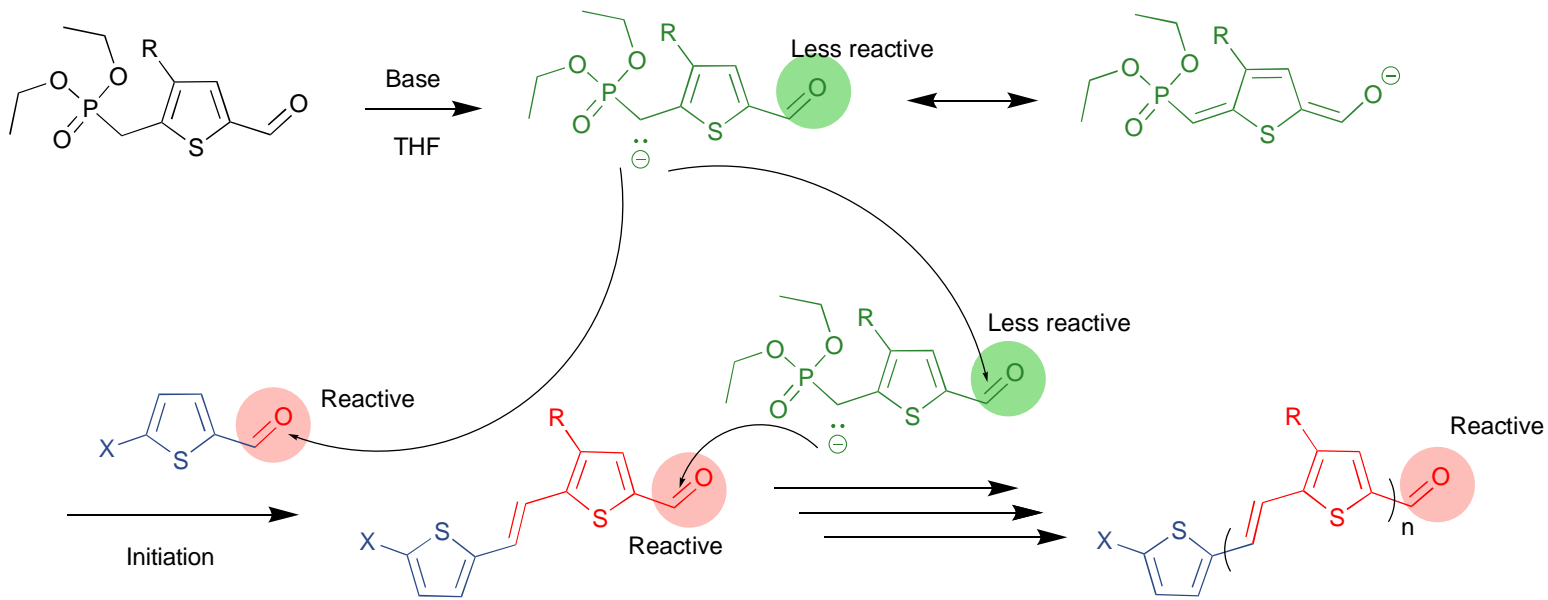

Scheme 9: Synthesis of thiophene-based $\pi$-conjugated polymer via HWE reaction (Adapted from Ref. ${ }^{43}$ with permission from The Royal Society of Chemistry)

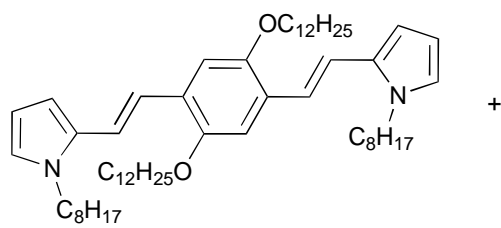<smiles>O=C1C(=O)C(O)C1O</smiles><smiles></smiles>

Scheme 10: Synthesis of polysquaraine (adapted from Ref. ${ }^{45}$ with permission of John Wiley and Sons, Inc.)
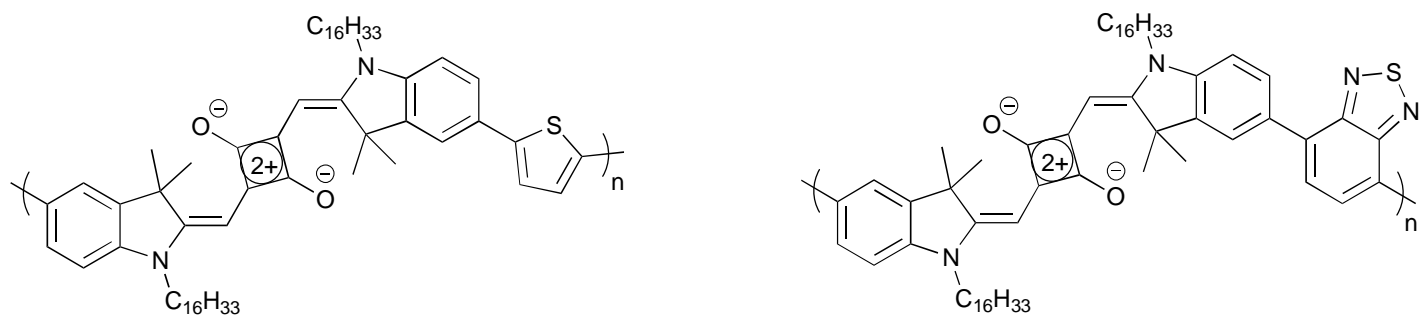

Figure 5: Structure of polysquaraines synthesized by either Stille/Suzuki coupling or condensation of squaric acid ${ }^{46}$

Please do not adjust margins 


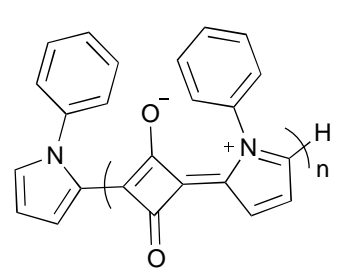

3<smiles>CC=C1C(=O)C(C=C2Cc3cc4c(cc3N2CCCS(=O)(=O)[O-])C(C)=[N+]4CCCS(=O)(=O)O)=C1[O-]</smiles>

4

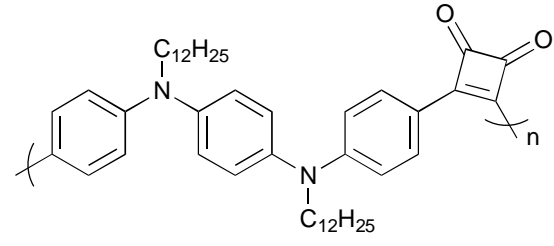

5

Figure 6: Structure of various polysquaraines $47,48,49$

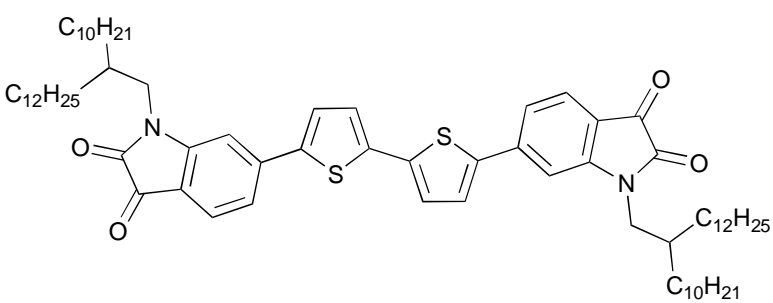

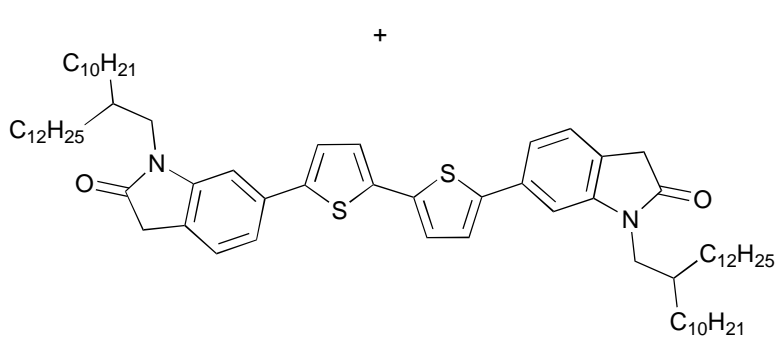

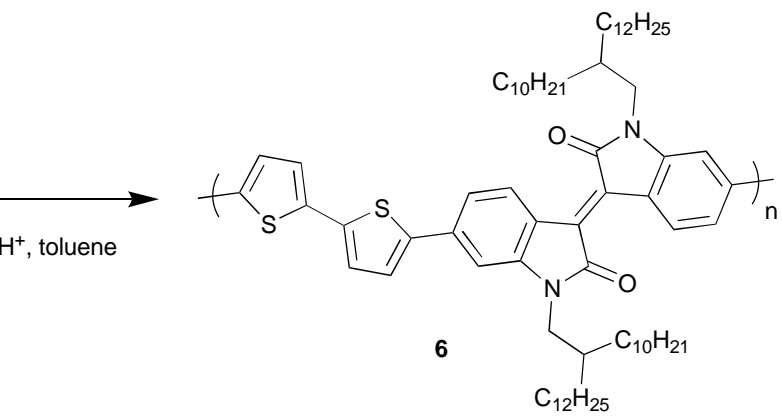

Scheme 11: Aldol condensation of isoindigo-based polymer (Reproduced from Ref. ${ }^{50}$ with permission from The Royal Society of Chemistry)

\subsubsection{Aldol condensation}

Zhang and coll. investigated the synthesis of an isoindigo-based polymer using aldol condensation, 50 as represented in Scheme $\mathbf{1 1 .}$ Aldol condensation is primarily used to synthesize small dyes ${ }^{51}$ - the authors claimed they were the first to use this route to prepare $\pi$ conjugated polymers. This method allows the synthesis of the polymer $\mathbf{6}$ without the use of any metallic catalyst with no branching defects. The latter polymer has been extensively studied and was also synthesized by transition-metal based coupling, such as Stille coupling (noted Polymer 6-S).52,53,54 Polymer $\mathbf{6}$ and polymer 6-S have similar absorbance properties. Surprisingly, OFET-based on polymer $\mathbf{6}$ showed lower properties than the one with polymer 6-S. The contrary was expected, as polymer $\mathbf{6}$ is supposed to contain less transition-metal impurities than polymer 6-S. Yet polymer $\mathbf{6}$ is not completely metal-free as a palladium-based catalyst was used to obtain the monomers by DHAP, as illustrated in Scheme 12. Zhang et al. claimed that the lower properties of polymer 6-based OFET are due to low $M_{n}$ values, or because of device optimization. Still, polymer 6 showed promising properties and was integrated in an OFET which exhibited a mobility of $0.16 \mathrm{~cm}^{2} \mathrm{~V}^{-1} \mathrm{~s}^{-1}$, and polymer 6-S was successfully integrated in solar cells with high PCE (up to 6.3\%)..$^{52}$ Aldol condensation is a promising reaction pathway that could be used to obtain various donor-acceptor $\pi$-conjugated polymers and possibly thieno-isoindigo-based polymers (Figure 7). Indeed, the link between the two halves of the thieno-isoindigo moiety is obtained by aldol condensation - then the polymer is obtained by Stille coupling. Thieno-isoindigo-based polymers exhibit a low band gap, absorbance in the near infrared and promising properties for photovoltaics or OFET (mobility up to $5.3 \times 10^{-3} \mathrm{~cm}^{2} \mathrm{~V}^{-1} \mathrm{~s}^{-1}$ ). ${ }^{55,56}$

\subsection{Transition metal-free syntheses: conclusion}

To avoid the use of transition-metal catalyst in the fabrication of $p$ conjugated polymers, various coupling strategies are available, with and without halogen atoms. The above-mentioned alternative coupling reactions are not as developed as Stille or Suzuki reactions - but they allow the syntheses of various original polymer structures sometimes not available by other coupling reactions. Another way to avoid the use of transition metal catalysts, that was not discussed herein, could be for instance to perform polymerization via electropolymerization 57,58 or vapor phase deposition ${ }^{59}$ of appropriate monomers. Nevertheless, such routes cannot offer a comparable palette of well-defined $\pi$-conjugated structures. In the coming section, we would like to enter in a new way of thinking the design of $\pi$-conjugated polymers through the use of biomass derivates. 


\section{Bio-based building blocks and ensuing $\pi$ - conjugated polymers}

\subsection{General description of lignocellulose}

Lignocellulose biomass corresponds to forestry biomass, crops and crop residues. The latter biomass is mainly composed of lignin, cellulose and hemicelluloses, with various percentages depending on the vegetal species (Figure 8). ${ }^{6}$ Cellulose is the most abundant biopolymer in Nature, and is composed of cellobiose repeating units. ${ }^{60}$ Cellulose has a crystalline structure, which enables to maintain the structure of the plant. On the contrary, hemicelluloses are branched polysaccharides with an amorphous morphology, the composition of which depending on the vegetal species ${ }^{61}$ Finally, lignin is an aromatic polymer with a complex structure that also depends on the plant species. Hemicelluloses act as a glue that binds cellulose and lignin together and the hydrophobicity of lignin and its phenolic structure protect the wood against external aggressions. ${ }^{62}$ Cellulose and hemicelluloses have various applications, mostly for the paper industry (500 million tons of paper estimated to be produced in 2020 $\left.{ }^{63}\right)$, and can also be used as biofuels. However, the latter industry still has many challenges to overpass as it is facing higher prices than anticipated for the raw materials, and a lowering of investment. Many biofuels start-ups have either failed or are actually using lignocellulosic biomass to synthesize specialty molecules. ${ }^{64}$ Apart from these two main applications, cellulose and hemicellulose can also be used in opto-electronic devices.

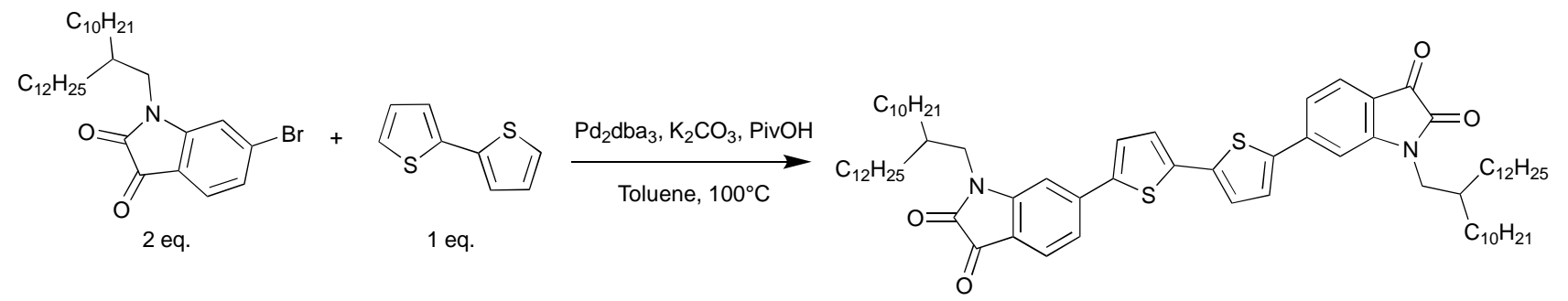

Scheme 12: Synthesis of isoindigo-based monomer via DHAP (Reproduced from Ref. ${ }^{50}$ with permission from The Royal Society of Chemistry)

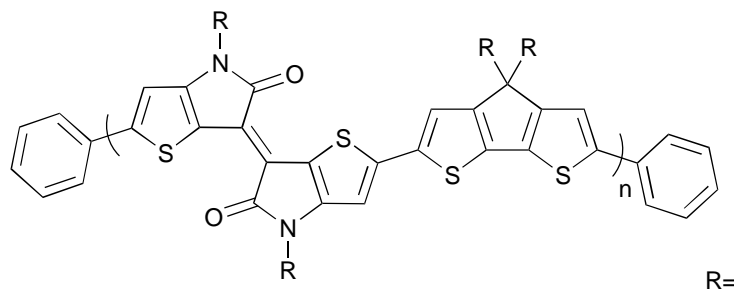

$R=2-E t h y|h e x y|$

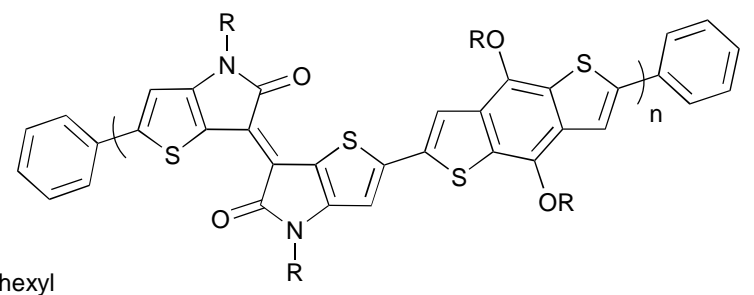

Figure 7: Thieno-isoindigo-based polymers ${ }^{55,56}$ 


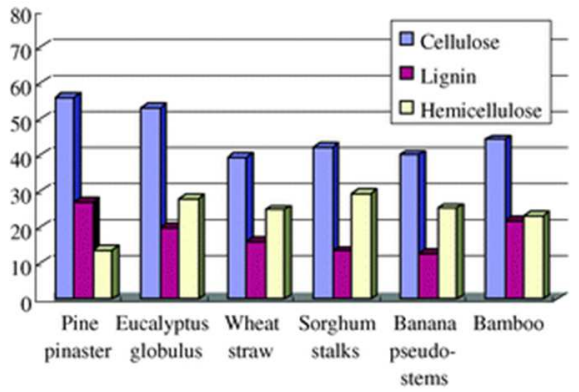

Figure 8: Weight percentages of cellulose, hemicelluloses and lignin in various plants (Reproduced from Ref. ${ }^{65}$ with permission from The Royal Society of Chemistry)

Karakawa et al. grafted fluorescent units on the available hydroxyl functions of cellulose, leading to a compound that was successfully integrated into an OLED. This grafted cellulose acts as an host material for the emissive layer of the device. ${ }^{66}$ Cellulose was also used as a substrate for various opto-electronic applications, to replace plastic. Thanks to its flexibility and transmittance in visible range, cellulose was integrated as a substrate for flexible OLED leading to efficient and promising devices with high brightness and efficiency. ${ }^{67,68}$ Qian et al. reported the fabrication of an OFET using cellulose as a flexible and biodegradable substrate, coated with chitosan, another bio-based polymer that can be obtained from shrimp shells. ${ }^{69}$ Chitosan acted as a smoothing layer, as the roughness of cellulosic paper can be an impediment to the use of paper as substrate for opto-electronic applications. ${ }^{70}$ As for lignin, the latter is mainly burnt to produce energy for the paper plant. However, it is estimated that 30-75 millions tons of lignin per day could be produced by the kraft pulp plants without affecting their energy needs (estimated for a plant that produces 0.5 billion of oven dried wood pulp (odw) annually ${ }^{71}$ ). When not burnt, lignin can be used as a cement dispersant, optimizing the latter properties. ${ }^{72,73}$ Lignin can also be depolymerized and used to produce various organic molecules, as will be exemplified in the next section.

\subsection{Aromatic molecules from lignin 3.2.1 General description}

Two main industrial processes are used to produce lignin: (i) Kraft process and (ii) bisulfite process. The Kraft process is used by the paper industry to obtain pulp but also resins and terpens. ${ }^{74}$ As mentioned previously, the lignin obtained as a black liquor is most of the time burnt to produce energy. In the bisulfite process, cellulose of higher purity can be obtained, and lignin is once more a by-product obtained as lignosulfonates. Borregaard Lignotech (Norway) and Rayonier (USA) are the main producers of lignosulfonates. Both of these chemical processes break chemical bonds of lignin, but they also create new ones. Subsequently other methods were tested to depolymerize lignin in a more controlled way and avoid unwanted bond formations or impurities. Amongst them, Organosolv process is the most industrially advanced, ${ }^{75}$ but others are also tested, like the enzymatic way. ${ }^{76,77}$ Once the lignin is isolated, it can be decomposed to obtain aromatic synthons. Two ways can be followed: (i) oxidation or (ii) reduction pathways. The reduction pathway can lead to benzene, toluene and xylene platform, ${ }^{78}$ while the oxidation route can lead to various other aromatic compounds, ${ }^{79}$ as represented in Figure 9. To consider such molecules as potential monomers, they have to be at least bi-functional. One way to bring this bifunctionality is to make dimers from C-C coupling. Caillol et al. recently reviewed the various ways to create such bonds. ${ }^{7}$ Following an enzymatic coupling strategy, Grelier and coll. developed a platform of vanillin dimers as promising building blocks for opto-electronic applications. ${ }^{80,81,82,83}$ The dimerization of vanillin is given in Scheme 13. This procedure requires nonhazardous solvents (water/acetone) and is done at room temperature. Divanillin is produced as the only product in high yield, and this reaction can be performed on a multigram scale. ${ }^{84,80}$ Vanillin is naturally synthesized in Nature by a climbing orchid and can be recovered after curing the pods. However, this process is long, slow and tedious, with a very low yield: $500 \mathrm{~kg}$ of vanilla pods are required to produce $1 \mathrm{~kg}$ of vanillin. ${ }^{85}$ Therefore natural vanillin is expensive and in 2019, its cost was around $500 \$$ per $\mathrm{kg} .{ }^{86}$ Another way to obtain vanillin is to derivatize petroleum-based guaiacol, 87 but more environmental-friendly and bio-sourced ways are available. Indeed, vanillin can be obtained from eugeno ${ }^{88}$ but also from lignosulfonates. The main producer of vanillin starting from lignosulfonates is Borregaard (Norway). Solvay also produces vanillin by bioconversion of ferulic acid from rice bran (Rhovanil89). In both cases, the obtained vanillin is used as a flavoring agent for the food industry. But vanillin was also widely developed as polymer precursor. ${ }^{90,91}$ Llevot et al. notably demonstrated that dimers of vanillin can easily undergo polymerization, leading to polyesters, ${ }^{84}$ epoxide networks, ${ }^{92}$ etc. Vanillin can also be used in the synthesis of $\pi$-conjugated polymers, as is described in the next section.

\subsubsection{Conjugated polymer from vanillin}

As stated previously, vanillin can easily be dimerized via enzymatic coupling. ${ }^{80}$ The team of Arndtsen investigated the synthesis of crossconjugated polymers via multi-components synthesis, and applied it with divanillin as a starting monomer. They improved the synthetic protocol, from palladium-catalyzed ${ }^{93}$ to transition-metal free, ${ }^{82}$ as illustrated in Scheme 14. First divanillin was reacted with an amine and integrated in a one-pot synthesis with an aromatic acid chloride and catechyl (PPh). Then a substituted alkene was added to finally yield the polymer. This multi-component synthesis enables high stepeconomy; its drawback would be the use of acyl chloride moiety. By modulating the acyl chloride moiety and the various substituents $\left(R^{1}\right.$, $R^{2}, R^{3}$, and $R^{4}$ ), a whole range of cross-conjugated polymers were obtained, with tunable optical properties. The most promising polymers are represented in Figure 10. Their absorbance maxima are rather low (in the near-UV range), but both polymers exhibited a strong fluorescence with a high quantum yield, heralding promising properties for ensuing OLED. ${ }^{94}$ 
<smiles>COc1cc(C(=O)O)cc(OC)c1O</smiles>

Syringic acid<smiles>COc1cc(C=O)cc(OC)c1O</smiles>

Syringaldehyde<smiles>Oc1ccccc1O</smiles>

Catechol<smiles>O=Cc1ccc(O)cc1</smiles><smiles>COc1cc(C=O)ccc1O</smiles>

4-Hydroxybenzaldehyde<smiles>COc1cc(C(=O)O)ccc1O</smiles>

Vanillinic acid<smiles>C=CCc1ccc(O)c(OC)c1</smiles>

Eugenol<smiles>O=C(O)/C=C/c1ccc(O)c(O)c1</smiles><smiles>COc1cc(/C=C/C(=O)O)ccc1O</smiles><smiles>O=C/C=C/c1ccccc1</smiles><smiles>O=C(O)/C=C/c1ccccc1</smiles>

Cinnamic acid

Figure 9: Structures of aromatic molecules that can be obtained from lignin 79,95,96,97<smiles>COc1cc(C=O)ccc1OCC(C)(C)C</smiles><smiles>COC1=CC(C=O)=CCC1=O</smiles><smiles>COC1CC(C=O)C=CC1=O</smiles><smiles>COC1C=C(C=O)C=CC1=O</smiles><smiles>CCC1C=C(C=O)C=C(OC)C1=O</smiles><smiles>COC1=CC(C=O)=CC(C2C=C(C=O)C=C(OC)C2=O)C1=O</smiles><smiles>COc1cc(C=O)cc(-c2cc(C=O)cc(OC)c2O)c1O</smiles>

Scheme 13: Laccase-catalyzed vanillin dimerization ${ }^{98}$ 

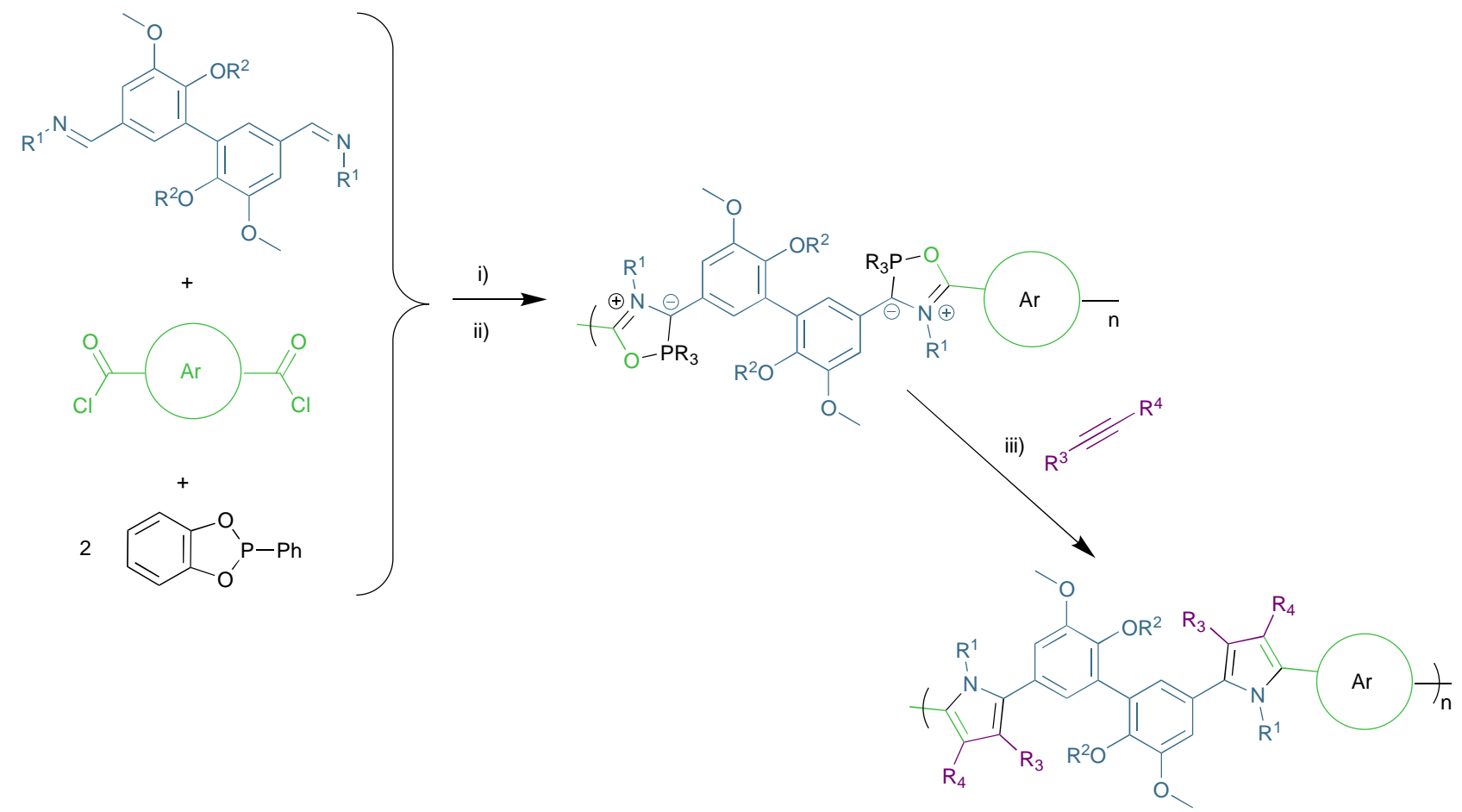

Scheme 14: Multi-components synthesis of divanillin-based polypyrrole (i) Dichloromethane, $45^{\circ} \mathrm{C}, 24 \mathrm{~h}$, ii) DBU, RT, 15 minutes, iii) RT, 18 hours) (adapted with permission from Ref ${ }^{82}$. Copyright (C2016, American Chemical Society) 
<smiles></smiles>

$\mathrm{M}_{\mathrm{n}}=6.3 \mathrm{kDa} \mathrm{PDI}=2.1$

$\lambda_{\max }(\mathrm{abs})=323 \mathrm{~nm}, \lambda_{\max }(\mathrm{em})=431 \mathrm{~nm}$ $\mathrm{QY}=0.66$<smiles></smiles>

$\mathrm{M}_{\mathrm{n}}=6.6 \mathrm{kDa} \mathrm{PDI}=1.7$

$\lambda_{\max }(\mathrm{abs})=296 \mathrm{~nm}, \lambda_{\max }(\mathrm{em})=449 \mathrm{~nm}$ $\mathrm{QY}=0.49$

Figure 10: Structure and characteristics of divanillin-based cross-conjugated polymers (molar masses determined by SEC in THF, and optical properties determined in chloroform, QY determined versus an anthracene standard) (adapted with permission from Ref. ${ }^{82}$. Copyright (C)2016, American Chemical Society)

Notably polymer $\mathbf{O}$ (see Fig. 10) was synthesized using furan 2,5dicarboxylic acid (FDCA), which can be obtained from 5-HMF (see Section 3.3.1.), paving the way towards fully biobased $\pi$-conjugated polymers. Other reactions are possible, for example by transposing the synthesis of vanillin-based small dyes to the synthesis of divanillin-based polymer, as illustrated in Scheme 15 with a Knoevenagel condensation. The obtained dyes were used as sensors for volatile amines. ${ }^{99}$ Another type of coupling using vanillin is the formation of Schiff base. ${ }^{100,101}$ The latter compounds have been intensively studied, but mostly for their antibacterial properties ${ }^{102}$ or as complexes. ${ }^{103}$

\subsection{Furan and its derivatives}

\subsubsection{General description}

Furan and its derivatives also gained massive interests as bio-based compounds. Indeed, the furan moiety is reported to yield polymers with high thermal stability ${ }^{104}$ and has promising properties for opto-<smiles>COc1cc(C=O)ccc1O</smiles>

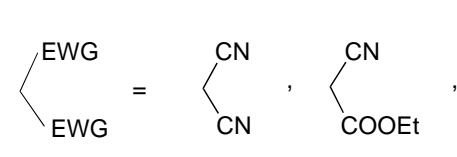<smiles>O=C1CC(=O)NC(=O)N1</smiles><smiles>CCN1C(=O)CC(=S)N(CC)C1=S</smiles><smiles>O=C1CC(=O)c2ccccc21</smiles>

Scheme 15: Synthesis of vanillin-based dyes via Knoevenagel condensation (adapted from ${ }^{99}$ )

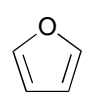

Furan<smiles>O=Cc1ccco1</smiles>

Furfural<smiles>O=Cc1ccc(CO)o1</smiles>

5-(HydroxyMethyl)Furfural<smiles>OCc1ccc(CO)o1</smiles>
2,5-Bis(Hydroxy
Methyl)Furan<smiles>Cc1ccc(C)o1</smiles>

2,5-DiMethyl Furan<smiles>C=Cc1ccc(CO)o1</smiles>

2-HydroxyMethyl 5-VinylFuran

Figure 11: Examples of furan-based compounds that can be obtained from bio-based resources ${ }^{6}$ 


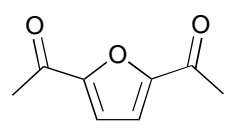

Furan-2,5Dicarboxylic Acid (FDCA)

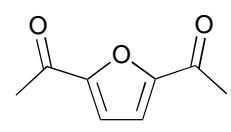

Furan-2,5-

Acyl Chloride

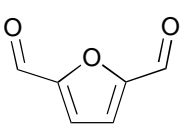

2,5-Diformylfuran

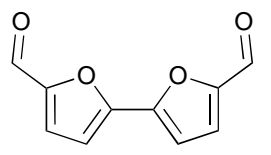

Difurfural

Figure 12: Structure of difunctional furan-based monomers

-electronic applications. The latter is structurally close to thiophene, one of the main building blocks for organic electronics. ${ }^{105}$ The furan moiety is believed to have superior properties than thiophene, as its oxygen atom is smaller than the sulfur one of thiophene. This size difference is expected to bring higher planarity and therefore more efficient $\pi$-stacking and charge transport; the furan moiety also enables strong fluorescence. ${ }^{106}$ Furfural can be obtained by dehydration of xylose, which can be derivatized from hemicellulose. 5-HydroxyMethylFurfural (5-HMF) is another furan-based compound that can be obtained by dehydration of sugars - it is also easily found in food products, ${ }^{107}$ and can be derivatized in 2,5-Dimethylfuran, a promising biofuel. ${ }^{108}$ By dehydrating 5-carbon sugars or derivatizing furfural or 5-HMF, various compounds are accessible: some are represented in Figure 11. These compounds can be used as monomers: 2,5- BishydroxymethylFuran was used as such in the course of polymerization, leading to self-healing polymer. ${ }^{109}$ Furanbased polymers can also be obtained by polymerizing a methacrylate furan-based compound, leading to polymers with furan as a pendant group. ${ }^{110} 5$-HMF can be derivatized as a dicarboxylic furan (Furan2,5-dicarboxylic acid, FDCA, in Figure 12); ${ }^{111}$ the latter led to various polyesters with promising properties that rival those of petroleumbased plastics. ${ }^{112,113,114}$ However, in these examples the $\pi$ conjugated structure of furan is not fully exploited. Furan-based monomers that could lead to $\pi$-conjugated polymers are represented in Figure 12. Furan-2,5-diacyl chloride can easily be obtained by derivatization of FDCA, in a single and solvent-free step. ${ }^{115} 2,5$-diformylfuran can be obtained by selective oxidation of $5-H M F$, but also in one step by derivatizing fructose. ${ }^{116,117}$ Finally, difurfural can be obtained by dimerization of bromofurfural under photoirradiation. The latter experimental protocol was improved by using bromofurfural as a photosensitive initiator, and furfural as the main reagent. The dimerization takes place between furfural molecules, leading to difurfural in good yield - subsequently this process was scaled-up. A reaction mechanism was proposed by the authors, and is represented in Scheme 16. ${ }^{118}$ This experimental protocol was published in 2000 and surprisingly no development could be found afterwards. Nowadays, reports on difurfural synthesis actually describe a longer experimental protocol, with a protection/deprotection step but also the use of palladium-based catalyst, 119,120 as shown in Scheme 17. Furan-based compounds are promising building blocks and could be comparable to thiophene and may even be better than the latter, thanks to their efficient $\pi$ stacking and strong fluorescence. In Figure 13, the simulation of HOMO and LUMO of difurfural shows how planar it can be, heralding promising opto-electronic properties. ${ }^{121}$

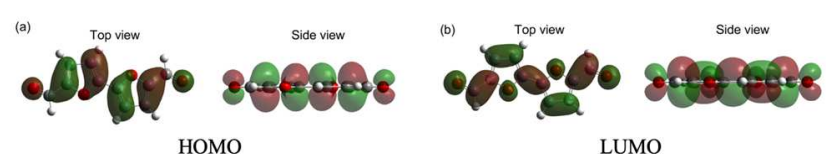

Figure 13: Optimized structure of electronic orbitals of difurfural (a. HOMO, b. LUMO) 119

\subsubsection{Furan-based $\pi$-conjugated polymer}

As mentioned previously, furan is a promising building block for the synthesis of $\pi$-conjugated polymers. ${ }^{122,123}$ Indeed, furan can exhibit similar and even superior properties to thiophene. ${ }^{106}$ One promising furan-based monomer is represented in Scheme 18, along with its ensuing polymer. This monomer can be obtained from cyano furan and the polymer is synthesized via Stille coupling. The latter polymer has a low band gap and was integrated in efficient OFET ${ }^{124,125}$ and solar cells. ${ }^{126,127} \mathrm{Ma}$ and coll. also synthesized a furan-based polymer, ${ }^{128}$ starting from biobased $5-\mathrm{HMF}$ as represented in Scheme 19. Interestingly, the benzoxazole-based monomer could be obtained from 3,4-AHBA. The polymer has a relatively low $M_{n}$ value (3 $900 \mathrm{~g} / \mathrm{mol}$, i.e. 6 units) but has a strong blue fluorescence, with a quantum yield of $0,57 .{ }^{128}$ Even if efforts were made to make the polymer's integration in devices ${ }^{125}$ or monomer's synthesis more sustainable, ${ }^{128}$ the coupling reactions still induce the presence of transition-metal impurities in the polymer, as well as the production of hazardous wastes. To avoid these issues, another way to obtain furan-based conjugated polymers is to synthesize polyazomethines. ${ }^{129}$ Xiang and coll. synthesized various furan-based polyazomethines, by using aromatic and aliphatic diamines, as represented in Scheme 20. . The polymerization was performed at room temperature without any catalysts. The polymer represented in Scheme $\mathbf{2 0}$ precipitated during polymerization, while the cyclic species 7 remained in solution. The structure of the latter was confirmed by mass spectroscopy. Solubility was an issue for the various polymers synthesized and subsequently the molar masses were determined by mass spectroscopy. The latter masses are rather low (6 repeating units), as the polymerization reaction is limited due to the precipitation of the polymers and the formation of cyclic species. A polyazomethine with aromatic diamines also exhibited low $M_{n}$ values and its optical properties were not extensively studied. Moreover, the latter is not fully $\pi$-conjugated - yet it has an absorbance maximum close to the visible range, heralding promising properties for a fully $\pi$-conjugated polyazomethine (Figure 14). ${ }^{130}$ 


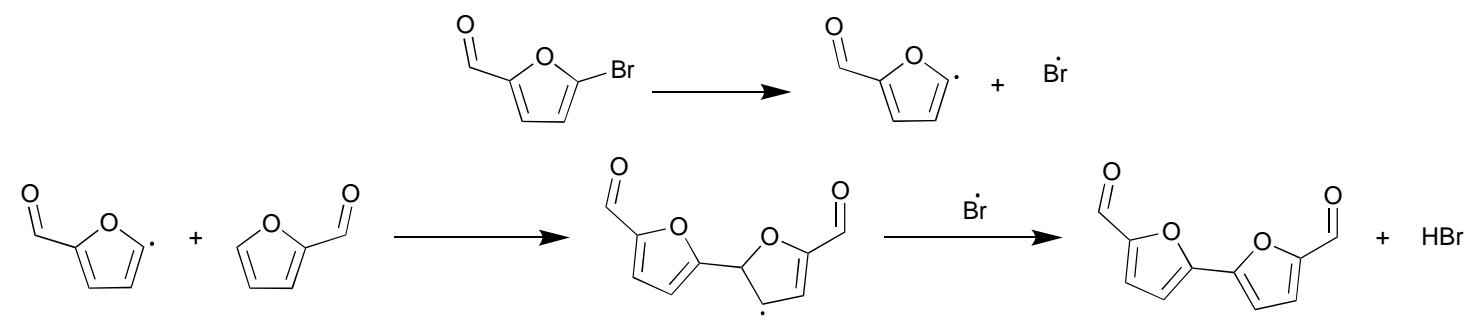

Scheme 16: Synthesis of difurfural via photochemistry (adapted from Ref. ${ }^{118}$ with permission from Elsevier)

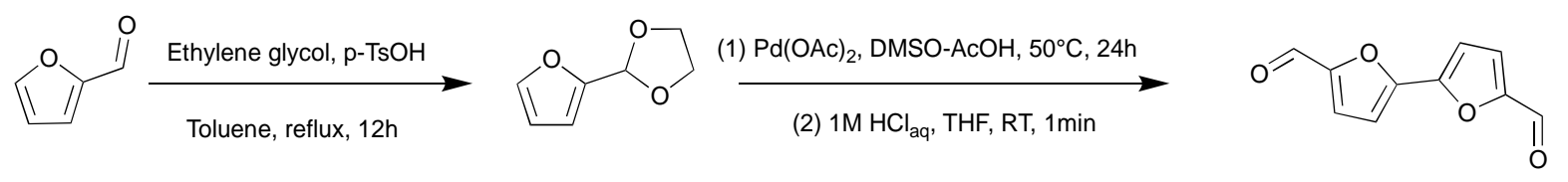

Scheme 17: Experimental protocol to obtain difurfural from furfural (Adapted from ${ }^{119}$ )<smiles>CCC(C)(C)CC(C)(O)CC</smiles><smiles>CCPn1c(=O)c2c(-c3ccc(Br)o3)c(-c3ccc(Br)o3)c-2c1=O</smiles><smiles></smiles>

$\mathrm{Me}_{3} \mathrm{Sn}$<smiles>CSc1cccs1</smiles>
P

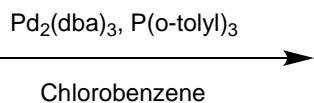

Chlorobenzene<smiles>[R]N1C(=O)C2=C(c3ccc(Br)o3)N(P)C(=O)C2=C1c1ccc(Br)o1</smiles>

Scheme 18: Synthesis of furan-based monomer and ensuing polymerization via Stille coupling (adapted with permission from Ref. 126 Copyright @2010, American Chemical Society) 


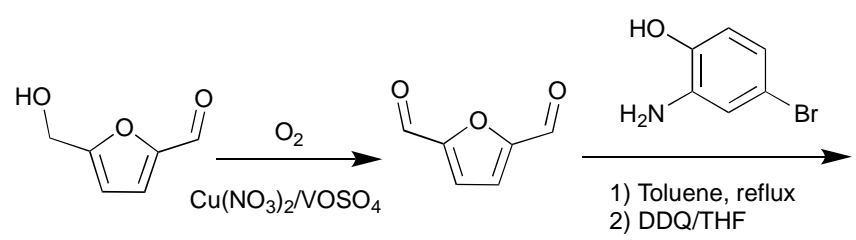<smiles>Brc1ccc2oc(-c3ccc(-c4nc5cc(Br)ccc5o4)o3)nc2c1</smiles><smiles>[R]C1([R])c2cc(B3OCCCO3)ccc2-c2ccc(B3OCCCO3)cc21</smiles>

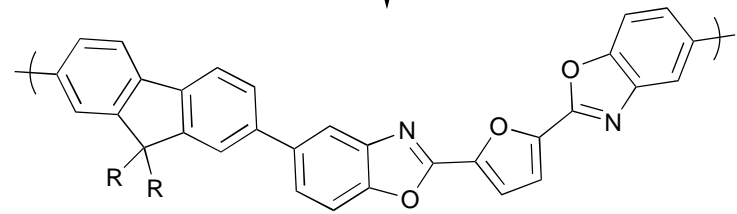

Scheme 19: Synthesis of furan-based monomer and polymer thereof via Suzuki coupling (adapted from ${ }^{128}$ with permission of John Wiley and Sons, Inc.)

Scheme 20: Synthesis of furan-based polyazomethines and cyclic specie obtained during polymerization (adapted from Ref. ${ }^{130}$ with permission of John Wiley and Sons, Inc.)

Tachibana et al. investigated the synthesis of difurfural-based polyazomethines. The authors synthesized difurfural through a palladium-based coupling reaction (Scheme 17) and then reacted it with various diamines, as represented in Figure 15 . The polymerization was performed in $\mathrm{m}$-cresol or in bulk but in both cases without any catalysts.

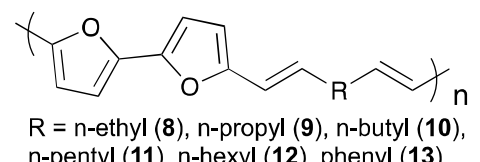

Figure 15: General structure of difurfural-based polyazomethines ${ }^{119}$

While not clearly measured, the $M_{n}$ values of the polymers are ranging from 1000 to $10000 \mathrm{~g} / \mathrm{mol}$ depending on the diamine. Interestingly, the formation of cyclics was also observed in this polymerization. Polymer $\mathbf{1 3}$ has an absorbance maximum at $442 \mathrm{~nm}$ - the authors did not optically characterize further these polyazomethines, as they were interested in their mechanical properties. $^{119}$

\subsection{3-amino-4-hydroxybenzoic acid, a renewable monomer produced by a microorganism}

3-amino-4-hydroxybenzoic acid, noted 3,4-AHBA, can be easily obtained by Streptomyces griseus, a microorganism found in sandy grounds. ${ }^{131}$ By implementing the correct DNA sequence, other microorganisms can also carry out the synthesis of 3,4-AHBA. ${ }^{132}$ The latter is a versatile monomer that can be easily polymerized through electropolymerization (Scheme 21). This method relies on a potential difference between two electrodes - the polymerization can occur either on the anode or the cathode, depending on the monomer. ${ }^{58,133}$ The polymer obtained bears strong similitudes with polyaniline (PANi), an intensively studied conducting polymer. The latter exhibits strong conductivity and stability and can be easily 
doped/de-doped under acidic/basic conditions. For example PANi can be used for biomedical applications ${ }^{134}$, but also as nanofibers. ${ }^{135,136}$ However PANi is poorly soluble in common solvents, which makes it harder to process. On the contrary, poly $(3,4-$ AHBA) is more soluble and its $M_{n}$ value was determined by SEC in THF (5500 g/mol, dispersity 1). Poly(3,4-AHBA) showed a behavior similar to PANi's, with halochromism but also solvatochromism. ${ }^{137}$
Another team synthesized poly(3,4-AHBA) via electropolymerization and obtained nanoparticles, by using different experimental conditions. The latter nanoparticles exhibit good $\mathrm{pH}$ sensitivity, even better than PANi's, thanks to the two additional pH-sensitive function on the monomer units: hydroxy and carboxylic acid. These nanoparticles could be used for electrochemical sensors and biosensors. ${ }^{138}$

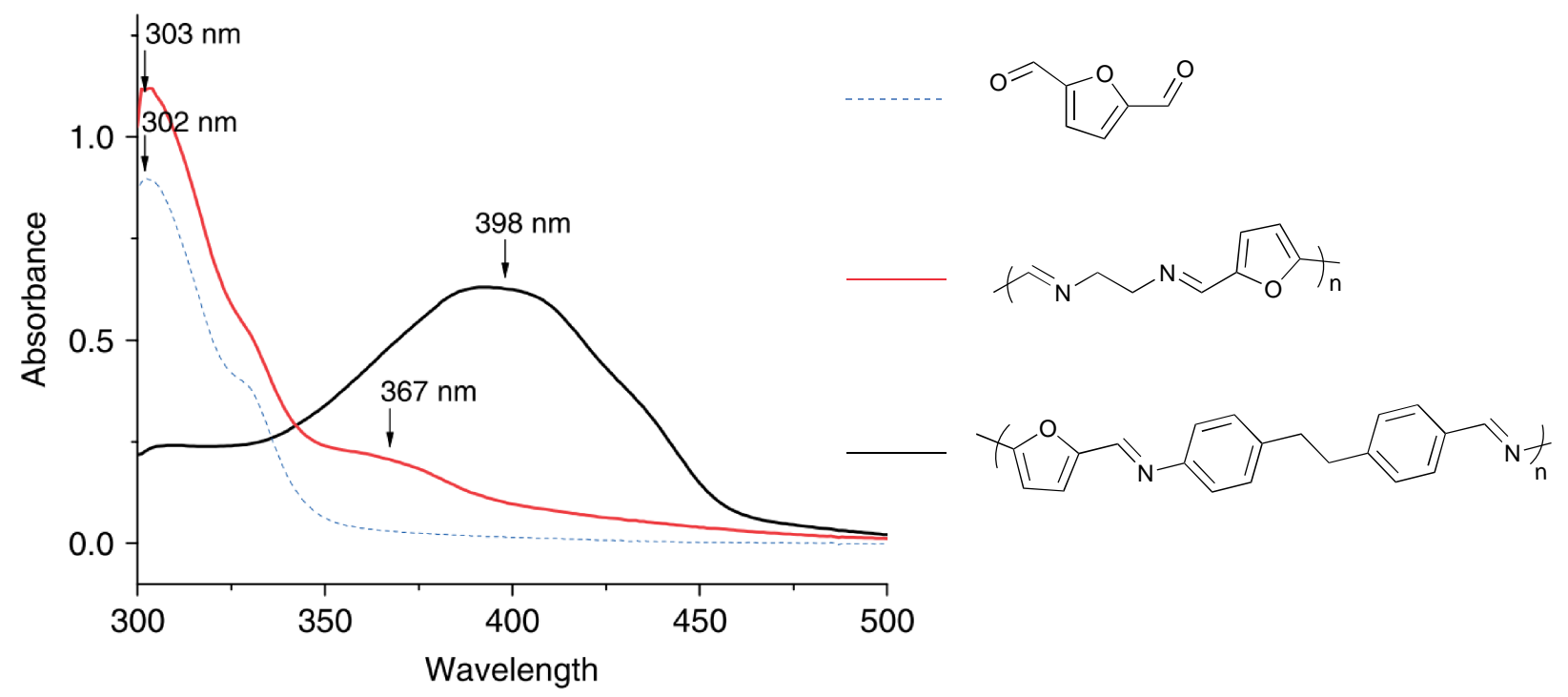

Figure 14: Absorbance spectra of dialdehyde furan and furan-based polyazomethines (in $m$-cresol) (adapted from Ref. ${ }^{130}$ with permission of John Wiley and Sons, Inc.)

3,4-AHBA can also be polymerized to form polybenzoxazoles. These polymers are mostly used for their high tensile strength, Young modulus and excellent thermal stability. Zylon (poly(p-phenylene2,6-benzobisoxazole) was used as ballistic vest for example. ${ }^{139}$ The synthesis of polybenzoxazoles from 3,4-AHBA was patented with the objective to use the polymer for its mechanical properties. ${ }^{140}$ Yet polybenzoxazoles are also promising conjugated polymers. Indeed, the polymer represented in Figure $\mathbf{1 6}$ was successfully used for fluorescent imaging and fluorescent patterning (synthesis performed via Suzuki coupling). ${ }^{141}$ Moreover benzoxazoles are well-known dyes, with bright fluorescence even in the solid state. ${ }^{142,143}$ An example of synthesis is given in Scheme 22. 3,4-AHBA could also be used to synthesize other types of $p$-conjugated polymers such as polybenzobisthiazoles and polythiazolothiazoles. It is noteworthy the presence of hydroxy groups that can further be alkylated in order to tune the solubility of ensuing polymers.

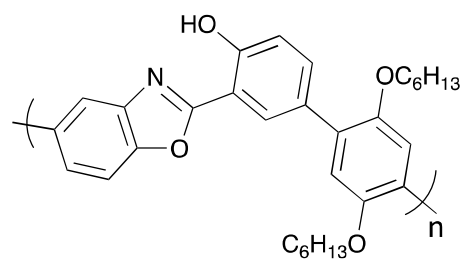

Figure 16: Polybenzoxazole used for fluorescent imaging and patterning ${ }^{141}$ 

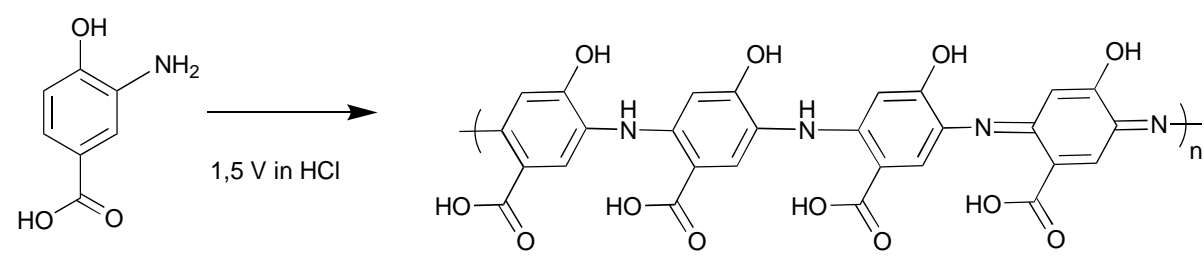

Scheme 21: Electropolymerization of 3,4-AHBA (adapted from ${ }^{137}$ )<smiles>O=Cc1ccc(O)c(C(=O)O)c1</smiles><smiles>Nc1ccccc1O</smiles>

Polyphosphoric acid $170^{\circ} \mathrm{C}, 5 \mathrm{~h}$<smiles>O=Cc1ccc(O)c(-c2nc3ccccc3o2)c1</smiles>

Scheme 22: Synthesis of benzoxazole dye (Reproduced from Ref. ${ }^{143}$ with permission from The Royal Society of Chemistry)

\subsection{Bio-based building blocks and ensuing polymers: conclusion}

Lignocellulosic biomass can provide a wide range of molecules, from phenol- to furan-based compounds but many others, mainly arenes or heteroarenes. ${ }^{144}$ Such biobased molecules can then undergo polymerization, leading to various polymers with promising optoelectronic features. We chose to focus on the compounds that could be used for organic electronics, namely with moieties that could bring $\pi$-conjugation: aromatic and furan-based molecules. Vanillin is an interesting compound, as it can be easily dimerized by an environmental friendly reaction. ${ }^{80}$ Another type of promising molecules for organic electronics is based on furan derivates that could be comparable to thiophene showing even stronger fluorescence. In Figure 13, the simulation of HOMO and LUMO of difurfural shows how planar it can be, heralding promising optoelectronic properties. ${ }^{121} \mathrm{~A}$ molecule issued from a microorganism, the 3,4-AHBA, is also showing good promises in the field.

\section{General conclusion}

The synthesis of $\pi$-conjugated polymers for organic electronics mainly relies on conventional coupling reactions, which implies the pollution of the final materials with residual transition metals. Other coupling reactions are accessible to avoid such impurities, and some were discussed in this review. Firstly, it is possible to avoid hazardous monomers via DHAP. This coupling, based on palladium catalyst, allows the formation of a $\mathrm{C}-\mathrm{C}$ bond between aryl moieties through halogen derivates. Some transition metal-free coupling reactions can be performed to synthesize $\pi$-conjugated polymers, such as bromine-catalyzed coupling ${ }^{24}$ and NMRP-mediated approach. ${ }^{26}$ Amongst others, the formation of azomethine bonds ${ }^{31}$ and the Knoevenagel reaction ${ }^{39}$ enable the synthesis of $\pi$-conjugated polymers without neither transition-metal nor halogen impurities. In the present review article, we also selected bio-based substrates having a good potential in the field of organic electronics, i.e. vanillin as well as furan and its derivatives. Indeed, both were used as promising monomers for the synthesis of various polymers (e.g. vanillin-based ${ }^{145,} 92$ and furan-based polyesters ${ }^{112}$ ) and are also promising building blocks for organic electronics. ${ }^{106} \mathrm{It}$ is obvious and promising that lignocellulosic biomass can be the source of a wide platform of substrates with various structures (aromatic, heterocyclic, linear, etc.) and functionalities (aldehyde, hydroxy and methoxy for example). To sum-up, while efforts have been made in parallel to design bio-based $\pi$-conjugated polymers or to develop alternative environment friendly routes to semiconducting polymers there is a great deal of room of development and progress in combining these two methodologies targeting more sustainable still efficient materials for organic electronics.

\section{Conflicts of interest}

There are no conflicts to declare.

\section{Acknowledgements}

Authors thank Solvay and the Région Nouvelle Aquitaine for the funding. Authors thank also ELORPrintTec (ANR-10-EQPX-2801) and LCPO / Arkema / ANR Industrial Chair 'HOMERIC' (ANR13-CHIN-0002-01)

\section{Notes and references}

¥ Footnotes relating to the main text should appear here. These might include comments relevant to but not central to the matter under discussion, limited experimental and spectral data, and crystallographic data. $\S$ 
etc.

1. Nehls, B. S. et al. Semiconducting polymers via microwaveassisted Suzuki and Stille cross-coupling reactions. Adv. Funct. Mater. 14, 352-356 (2004).

2. Milstein, D. \& Stille, J. K. A General, Selective, and Facile Method for Ketone Synthesis from Acid Chlorides and Organotin Compounds Catalyzed by Palladium. J. Am. Chem. Soc. 100, 3636-3638 (1978).

3. Usluer, Ö. et al. Metal residues in semiconducting polymers: Impact on the performance of organic electronic devices. ACS Macro Lett. 3, 1134-1138 (2014).

4. Marrocchi, A., Facchetti, A., Lanari, D., Petrucci, C. \& Vaccaro, L. Current methodologies for a sustainable approach to $\pi$-conjugated organic semiconductors. Energy Environ. Sci. 9, 763-786 (2016).

5. Nagel, B., Dellweg, H. \& Gierasch, L. M. Glossary for chemists of terms used in biotechnology. Pure Appl. Chem. 64, 143-168 (1992).

6. Isikgor, F. H. \& Becer, C. R. Lignocellulosic biomass: a sustainable platform for the production of bio-based chemicals and polymers. Polym. Chem. 6, 4497-4559 (2015).

7. Decostanzi, M., Auvergne, R., Boutevin, B. \& Caillol, S. Biobased phenol and furan derivative coupling for the synthesis of functional monomers. Green Chem. 21, 724747 (2019).

8. Bozell, J. J. \& Petersen, G. R. Technology development for the production of biobased products from biorefinery carbohydrates - The US Department of Energy's 'top 10' revisited. Green Chem. 12, 539-554 (2010).

9. Mercier, L. G. \& Leclerc, M. Direct (hetero)arylation: A new tool for polymer chemists. Acc. Chem. Res. 46, 1597-1605 (2013).

10. Sévignon, M., Papillon, J., Schulz, E. \& Lemaire, M. New synthetic method for the polymerization of alkylthiophenes. Tetrahedron Lett. 40, 5873-5876 (1999).

11. lizuka, E., Wakioka, M. \& Ozawa, F. Mixed-ligand approach to palladium-catalyzed direct arylation polymerization: Synthesis of donor-acceptor polymers with dithienosilole (DTS) and thienopyrroledione (TPD) units. Macromolecules 48, 2989-2993 (2015).

12. Biswas, B., Sugimoto, M. \& Sakaki, S. C-H Bond Activation of Benzene and Methane by $\mathrm{M}(\mathrm{n} 2-\mathrm{O} 2 \mathrm{CH}) 2(\mathrm{M}) \mathrm{Pd}$ or Pt). A Theoretical Study. Organometallics 19, 3895-3908 (2000).

13. Morin, P. O. et al. Conjugated polymers à la carte from time-controlled direct (hetero)arylation polymerization ACS Macro Lett. 4, 21-24 (2015).

14. Fujinami, Y., Kuwabara, J., Lu, W., Hayashi, H. \& Kanbara, T. Synthesis of thiophene- and bithiophene-based alternating copolymers via $\mathrm{Pd}$-catalyzed direct $\mathrm{C}-\mathrm{H}$ arylation. $A C S$ Macro Lett. 1, 67-70 (2012).

15. Lombeck, F., Komber, H., Gorelsky, S. I. \& Sommer, M. Identifying homocouplings as critical side reactions in direct arylation polycondensation. ACS Macro Lett. 3, 819823 (2014).

16. Kuwabara, J. et al. Direct arylation polycondensation: A promising method for the synthesis of highly pure, high- molecular-weight conjugated polymers needed for improving the performance of organic photovoltaics. Adv. Funct. Mater. 24, 3226-3233 (2014).

17. Robitaille, A., Jenekhe, S. A. \& Leclerc, M. Poly(naphthalene diimide- alt-bithiophene) Prepared by Direct

(Hetero)arylation Polymerization for Efficient All-Polymer Solar Cells. Chem. Mater. 30, 5353-5361 (2018).

18. Leclerc, M., Brassard, S. \& Beaupré, S. Direct (hetero)arylation polymerization: toward defect-free conjugated polymers. Polym. J. (2019). doi:10.1038/s41428-019-0245-9

19. Bura, T. et al. Direct heteroarylation polymerization: Guidelines for defect-free conjugated polymers. Chem. Sci. 8, 3913-3925 (2017).

20. Mei, J., Graham, K. R., Stalder, R. \& Reynolds, J. R. Synthesis of isoindigo-based oligothiophenes for molecular bulk heterojunction solar cells. Org. Lett. 12, 660-663 (2010).

21. Kuwabara, J., Yasuda, T., Takase, N. \& Kanbara, T. Effects of the Terminal Structure, Purity, and Molecular Weight of an Amorphous Conjugated Polymer on Its Photovoltaic Characteristics. ACS Appl. Mater. Interfaces 8, 1752-1758 (2016).

22. Lu, W., Kuwabara, J. \& Kanbara, T. Polycondensation of dibromofluorene analogues with tetrafluorobenzene via direct arylation. Macromolecules 44, 1252-1255 (2011).

23. Grenier, F. et al. Electroactive and photoactive poly[isoindigo-alt-EDOT] synthesized using direct (hetero)arylation polymerization in batch and in continuous flow. Chem. Mater. 27, 2137-2143 (2015).

24. Patra, A. et al. Metal Free Conducting PEDOS, PEDOT, and Their Analogues via an Unusual Bromine-Catalyzed Polymerization. Macromolecules 48, 8760-8764 (2015).

25. Heeney, M. et al. Regioregular poly(3-hexyl)selenophene: A low band gap organic hole transporting polymer. Chem. Commun. 5061-5063 (2007). doi:10.1039/b712398a

26. Maji, M. S., Pfeifer, T. \& Studer, A. Transition-metal-free synthesis of conjugated polymers from bis-grignard reagents by using TEMPO as Oxidant. Chem. - A Eur. J. 16, 5872-5875 (2010).

27. Huang, L., Wu, S., Qu, Y., Geng, Y. \& Wang, F. Grignard Metathesis Chain-Growth Polymerization for Polyfluorene. Macromolecules 41, 8944-8947 (2008).

28. Mallet, C., Bolduc, A., Bishop, S., Gautier, Y. \& Skene, W. G. Unusually high fluorescence quantum yield of a homopolyfluorenylazomethine - towards a universal fluorophore. Phys. Chem. Chem. Phys. 16, 24382-24390 (2014).

29. Grankowska Ciechanowicz, S. et al. Toward Better Efficiency of Air-Stable Polyazomethine-Based Organic Solar Cells Using Time-Resolved Photoluminescence and Light-Induced Electron Spin Resonance as Verification Methods. J. Phys. Chem. C 120, 11415-11425 (2016).

30. Gawlinska, K. et al. Searching of new, cheap, air- and thermally stable hole transporting materials for perovskite solar cells. Opto-electronics Rev. 25, 274-284 (2017).

31. Bolduc, A., Mallet, C. \& Skene, W. G. Survey of recent 
advances of in the field of $\pi$-conjugated heterocyclic azomethines as materials with tuneable properties. Sci. China Chem. 56, 3-23 (2013).

32. Yang, C. J. \& Jenekhe, S. A. Conjugated Aromatic Poly(azomethines). 1. Characterization of Structure, Electronic Spectra, and Processing of Thin Films from Soluble Complexes. Chem. Mater. 3, 878-887 (1991).

33. Barik, S., Bletzacker, T. \& Skene, W. G. $\pi$-Conjugated fluorescent azomethine copolymers: Opto-electronic, halochromic, and doping properties. Macromolecules 45, 1165-1173 (2012).

34. Barik, S. \& Skene, W. G. A fluorescent all-fluorene polyazomethine-towards soluble conjugated polymers exhibiting high fluorescence and electrochromic properties. Polym. Chem. 2, 1091-1097 (2011).

35. Mallet, C., Le Borgne, M., Starck, M. \& Skene, W. G. Unparalleled fluorescence of a polyazomethine prepared from the self-condensation of an automer and its potential use as a fluorimetric sensor for explosive detection. Polym. Chem. 4, 250-254 (2013).

36. Greenham, N. C., Moratti, S. C., Bradley, D. D. C., Friend, R. H. \& Holmes, A. B. Efficient light-emitting diodes based on polymers with high electron affinities. Nature 365 , 628630 (1993).

37. Pang, Y. Design and Synthesis of Conjugated Polymers - Ch. 4. (Wiley - VCH, 2010).

38. Jakubiak, R., Collison, C. J., Chou, W. A., Rothberg, L. J. \& Hsieh, B. R. Aggregation quenching of luminescence in electroluminescent conjugated polymers. J. Phys. Chem. A 103, 2394-2398 (1999).

39. Cao, X. et al. A fluorescent conjugated polymer photocatalyst based on Knoevenagel polycondensation for hydrogen production. New J. Chem. 43, 7093-7098 (2019).

40. Liao, L., Pang, Y., Ding, L. \& Karasz, F. E. Blue-emitting soluble poly( $\mathrm{m}$-phenylenevinylene) derivatives.

Macromolecules 34, 7300-7305 (2001).

41. Van De Wetering, K., Brochon, C., Ngov, C. \& Hadziioannou, $G$. Design and synthesis of a low band gap conjugated macroinitiator: Toward rod-coil donor-acceptor block copolymers. Macromolecules 39, 4289-4297 (2006).

42. Liao, L. et al. Synthesis and luminescence of yellow/orangeemitting poly[tris(2,5-dihexyloxy-1,4-phenylenevinylene)alt-(1,3-phenylenevinylene)]s. J. Polym. Sci. Part A Polym. Chem. 42, 5853-5862 (2004).

43. Goto, E., Ochiai, Y., Ueda, M. \& Higashihara, T. Transitionmetal-free and halogen-free controlled synthesis of poly(3alkylthienylene vinylene): Via the Horner-WadsworthEmmons condensation reaction. Polym. Chem. 9, 19962001 (2018).

44. Ajayaghosh, A. Chemistry of squaraine-derived materials: Near-IR dyes, low band gap systems, and cation sensors. Acc. Chem. Res. 38, 449-459 (2005).

45. Broggi, A. et al. Squaraine-Based Polymers: Toward Optimized Structures for Optoelectronic Devices.

Macromol. Chem. Phys. 218, 1-9 (2017).

46. Oriou, J. et al. Synthesis of squaraine-based alternated $\pi$ conjugated copolymers: From conventional cross-coupling reactions to metal-free polycondensation. Polym. Chem. 5, 7100-7108 (2014).

47. Zhou, J. et al. Surface modification of polysquaraines to sense humidity within a second for breath monitoring. Sensors Actuators, B Chem. 271, 137-146 (2018).

48. Havinga, E. E., Pomp, A., ten Hoeve, W. \& Wynberg, H. Water-soluble polysquaraines and polycroconaines. Synth. Met. 69, 581-582 (1995).

49. Garbay, G. et al. Triaryl-1,4-diamine-based polysquaraines: Effect of co-solvent and monomer insertion on optoelectronic properties. Polym. Chem. 9, 1288-1292 (2018).

50. Zhang, G. et al. Facile green synthesis of isoindigo-based conjugated polymers using aldol polycondensation. Polym. Chem. 8, 3448-3456 (2017).

51. Mei, J., Graham, K. R., Stalder, R. \& Reynolds, J. R. Synthesis of isoindigo-based oligothiophenes for molecular bulk heterojunction solar cells. Org. Lett. 12, 660-663 (2010).

52. Wang, E. et al. An Easily Accessible Isoindigo-Based Polymer for High-Performance Polymer Solar Cells. J. Am. Chem. Soc. 133, 14244-14247 (2011).

53. Stalder, R., Mei, J., Graham, K. R., Estrada, L. A. \& Reynolds, J. R. Isoindigo, a versatile electron-deficient unit for highperformance organic electronics. Chem. Mater. 26, 664678 (2014).

54. Guo, C., Sun, B., Quinn, J., Yan, Z. \& Li, Y. Synthesis and properties of indigo based donor - acceptor conjugated polymers †. 4289-4296 (2014). doi:10.1039/c3tc32276a

55. Koizumi, Y. et al. Thienoisoindigo-based low-band gap polymers for organic electronic devices. Polym. Chem. 4, 484 (2013).

56. Ide, M. et al. Near-infrared absorbing thienoisoindigobased copolymers for organic photovoltaics. J. Phys. Chem. C 117, 26859-26870 (2013).

57. Konkol, K. L., Schwiderski, R. L. \& Rasmussen, S. C. Synthesis, characterization, and electropolymerization of extended fused-ring thieno[3,4-b]pyrazine-based terthienyls. Materials (Basel). 9, (2016).

58. Sayyah, S. M., El-Rabiey, M. M., Abd El-Rehim, S. S. \& Azooz, R. E. Electropolymerization kinetics of oaminophenol and characterization of the obtained polymer films. J. Appl. Polym. Sci. 99, 3093-3109 (2006).

59. Bilger, D., Homayounfar, S. Z. \& Andrew, T. L. A critical review of reactive vapor deposition for conjugated polymer synthesis. J. Mater. Chem. C 7, 7159-7174 (2019).

60. O'Sullivan, A. C. Cellulose: the structure slowly unravels. Cellulose 4, 173-207 (1997).

61. Puls, J. Chemistry and biochemistry of hemicelluloses: Relationship between hemicellulose structure and enzymes required for hydrolysis. Macromol. Symp. 120, 183-196 (1997).

62. Ithal, N. et al. Developmental transcript profiling of cyst nematode feeding cells in soybean roots. Mol. PlantMicrobe Interact. 20, 510-525 (2007).

63. Gopal, P. M., Sivaram, N. M. \& Barik, D. Paper Industry Wastes and Energy Generation From Wastes. Energy from 
Toxic Organic Waste for Heat and Power Generation (Elsevier Ltd., 2019). doi:10.1016/b978-0-08-1025284.00007-9

64. Lynd, L. R. The grand challenge of cellulosic biofuels. Nat. Biotechnol. 35, 912-915 (2017).

65. Zhou, C. H., Xia, X., Lin, C. X., Tong, D. S. \& Beltramini, J. Catalytic conversion of lignocellulosic biomass to fine chemicals and fuels. Chem. Soc. Rev. 40, 5588-5617 (2011).

66. Karakawa, M. et al. Organic light-emitting diode application of fluorescent cellulose as a natural polymer. Macromol. Chem. Phys. 208, 2000-2006 (2007).

67. Purandare, S., Gomez, E. F. \& Steckl, A. J. High brightness phosphorescent organic light emitting diodes on transparent and flexible cellulose films. Nanotechnology 25, (2014).

68. Min, S. H., Kim, C. K., Lee, H. N. \& Moon, D. G. An OLED using cellulose paper as a flexible substrate. Mol. Cryst. Liq. Cryst. 563, 159-165 (2012).

69. Qian, C., Sun, J., Yang, J. \& Gao, Y. Flexible organic fieldeffect transistors on biodegradable cellulose paper with efficient reusable ion gel dielectrics. RSC Adv. 5, 1456714574 (2015).

70. Kurra, N., Dutta, D. \& Kulkarni, G. U. Field effect transistors and RC filters from pencil-trace on paper. Phys. Chem. Chem. Phys. 15, 8367-8372 (2013).

71. Berlin, A. \& Balakshin, M. Industrial Lignins: Analysis, Properties, and Applications. Bioenergy Research: Advances and Applications (Elsevier, 2014). doi:10.1016/B978-0-44459561-4.00018-8

72. Sengupta, ashoke K., Gargulak, J., Bushar, L. \& Zajakowski, $\mathrm{V}$. Low retarding, high fluidity producing lignin dispersant for concrete. (2001).

73. Otani, S., Fukuoka, K., Fukuoka, Y., Igarashi, B. \& Sasaki, T. Method for Producing Carbonized Lignin Fiber. (1969).

74. Chakar, F. S. \& Ragauskas, A. J. Review of current and future softwood kraft lignin process chemistry. Ind. Crops Prod. 20, 131-141 (2004).

75. Muurinen, E. S. A. Organosolv Pulping A review and distillation study related to peroxyacid pulping. (University of Oulu, 2000).

76. Rakotovelo, A. Fragmentation enzymatique de la lignine pour l'obtention de synthons phénoliques. (Université de Bordeaux, 2016).

77. Hämäläinen, V. et al. Enzymatic processes to unlock the lignin value. Front. Bioeng. Biotechnol. 6, 1-10 (2018).

78. Huber, G. W., Iborra, S. \& Corma, A. Synthesis of transportation fuels from biomass: Chemistry, catalysts, and engineering. Chem. Rev. 106, 4044-4098 (2006).

79. Lange, H., Decina, S. \& Crestini, C. Oxidative upgrade of lignin - Recent routes reviewed. Eur. Polym. J. 49, 11511173 (2013).

80. Llevot, A., Grau, E., Carlotti, S., Grelier, S. \& Cramail, H. Selective laccase-catalyzed dimerization of phenolic compounds derived from lignin: Towards original symmetrical bio-based (bis) aromatic monomers. J. Mol. Catal. B Enzym. 125, 34-41 (2016).

81. Chithambarathanu, T., Vanaja, K. \& Magdaline, J. D.
Molecular structure, spectroscopic studies, HOMO-LUMO profile and NBO analysis of 3-Ethoxy-4-hydroxy benzaldehyde. Rasayan J. Chem. 8, 490-508 (2015).

82. Kayser, L. V., Hartigan, E. M. \& Arndtsen, B. A. Multicomponent Coupling Approach to Cross-Conjugated Polymers from Vanillin-Based Monomers. ACS Sustain. Chem. Eng. acssuschemeng.6b02302 (2016). doi:10.1021/acssuschemeng.6b02302

83. Andraud, C. et al. Theoretical and experimental investigations of the nonlinear optical properties of vanillin, polyenovanillin, and bisvanillin derivatives. J. Am. Chem. Soc. 116, 2094-2102 (1994).

84. Llevot, A. Resinic acid and lignin derivative dimers: new precursors for the synthesis of biobased polymers. (Université de Bordeaux, 2014).

85. Gallage, N. J. et al. Vanillin formation from ferulic acid in Vanilla planifolia is catalysed by a single enzyme. Nat. Commun. 5, (2014).

86. Gelski, J. Vanilla prices slowly drop as crop quality improves. Food Business News 1, 27-28 (2019).

87. Reimer, K. Ueber eine neue Bildungsweise aromatischer Aldehyde. Berichte der Dtsch. Chem. Gesellschaft 9, 423424 (1876).

88. Hocking, M. B. Vanillin: Synthetic flavoring from spent sulfite liquor. J. Chem. Educ. 74, 1055-1059 (1997).

89. Solvay. Rhovanil ${ }^{\circledR}$ Natural CW | Solvay.

90. Fache, M. et al. Vanillin, a promising biobased buildingblock for monomer synthesis. Green Chem. 16, 1987-1998 (2014).

91. Fache, M., Boutevin, B. \& Caillol, S. Vanillin, a keyintermediate of biobased polymers. Eur. Polym. J. 68, 488502 (2015).

92. Savonnet, E., Grau, E., Grelier, S., Defoort, B. \& Cramail, H. Divanillin-Based Epoxy Precursors as DGEBA Substitutes for Biobased Epoxy Thermosets. ACS Sustain. Chem. Eng. 6, 11008-11017 (2018).

93. Leitch, D. C. et al. A palladium-catalysed multicomponent coupling approach to conjugated poly(1,3-dipoles) and polyheterocycles. Nat. Commun. 6, 1-8 (2015).

94. Camurlu, P. Polypyrrole derivatives for electrochromic applications. RSC Adv. 4, 55832-55845 (2014).

95. van Haveren, J., Scott, E. L. \& Sanders, J. Bulk chemicals from biomass. Biofuels, Bioprod. Biorefining 2, 41-57 (2008).

96. Rahimi, A., Ulbrich, A., Coon, J. J. \& Stahl, S. S. Formic-acidinduced depolymerization of oxidized lignin to aromatics. Nature 515, 249-252 (2014).

97. Arevalo-Gallegos, A., Ahmad, Z., Asgher, M., Parra-Saldivar, R. \& Iqbal, H. M. N. Lignocellulose: A sustainable material to produce value-added products with a zero waste approach-A review. Int. J. Biol. Macromol. 99, 308-318 (2017).

98. Antoniotti, S., Santhanam, L., Ahuja, D., Hogg, M. G. \& Dordick, J. S. Structural diversity of peroxidase-catalyzed oxidation products of o-methoxyphenols. Org. Lett. 6, 1975-1978 (2004).

99. Asiri, A., Baghaffar, G., Al-Harby, A. \& Zayed, M.-A. 
Synthesis of Some Vanillin Derivatives and their Use as an Optical Sensor for the Detection of Volatile Organic Compounds. J. King Abdulaziz Univ. 21, 117-128 (2009).

100. E. A. Dikusar, V. I. P. N. G. K. and A. P. Y. Synthesis of N,N'bis-[3-alkoxy-4-(hydroxy, alkoxy, acyloxy)phenylmethylene- and -Phenylmethyl]-1,3phenylenediamines. J. Pept. Sci. 60, 58-60 (2001).

101. Dikusar, E. A., Kozlov, N. G., Potkin, V. I., Azarko, V. A. \& Yuvchenko, A. P. Synthesis, film-forming properties, and thermal and light sensitivity of $\mathrm{N}, \mathrm{N}^{\prime}$-bis[4-hydroxy(alkoxy, acyloxy)-3-alkoxyphenylmethylidene]benzene-1,4diamines. Russ. J. Gen. Chem. 78, 281-285 (2008).

102. Petrović, Z. D., Orović, J., Simijonović, D., Petrović, V. P. \& Marković, Z. Experimental and theoretical study of antioxidative properties of some salicylaldehyde and vanillic Schiff bases. RSC Adv. 5, 24094-24100 (2015).

103. Laye, R. H. Syntheses and photophysical properties of a series of [2:2] silver(I) metallocycles. Inorganica Chim. Acta 360, 439-447 (2007).

104. Vasiliou, A. G., Nimlos, M. R., Daily, J. W. \& Ellison, G. B. Thermal decomposition of furan generates propargyl radicals. J. Phys. Chem. A 113, 8540-8547 (2009).

105. Perepichka, I. F., Perepichka, D. F. \& Meng, H. Handbook of Thiophene-Based Materials: Applications in Organic Electronics and Photonics. (2009). doi:10.1002/9780470745533.ch19

106. Zhao, Z. et al. Furan Is Superior to Thiophene: A FuranCored AlEgen with Remarkable Chromism and OLED Performance. Adv. Sci. 4, 1-8 (2017).

107. Shapla, U. M., Solayman, M., Alam, N., Khalil, M. I. \& Gan, S. H. 5-Hydroxymethylfurfural (HMF) levels in honey and other food products: effects on bees and human health. Chem. Cent. J. 12, 1-18 (2018).

108. Eldeeb, M. A. \& Akih-Kumgeh, B. Recent trends in the production, combustion and modeling of furan-based fuels. Energies 11, 1-47 (2018).

109. Zeng, C., Seino, H., Ren, J., Hatanaka, K. \& Yoshie, N. Biobased furan polymers with self-healing ability. Macromolecules 46, 1794-1802 (2013).

110. He, J., Zhang, Y. \& Chen, E. Y. X. Anionic polymerization of biomass-derived furfuryl methacrylate: Controlling polymer tacticity and thermoreversibility. J. Polym. Sci. Part A Polym. Chem. 51, 2793-2803 (2013).

111. Sajid, M., Zhao, X. \& Liu, D. Production of 2,5furandicarboxylic acid (FDCA) from 5hydroxymethylfurfural (HMF): Recent progress focusing on the chemical-catalytic routes. Green Chem. 20, 5427-5453 (2018).

112. Sousa, A. F. et al. Biobased polyesters and other polymers from 2,5-furandicarboxylic acid: A tribute to furan excellency. Polym. Chem. 6, 5961-5983 (2015).

113. De Jong, E., Dam, M. A., Sipos, L. \& Gruter, G. J. M. Furandicarboxylic acid (FDCA), A versatile building block for a very interesting class of polyesters. ACS Symp. Ser. 1105, 1-13 (2012).

114. E4tech (UK) for LBNet. UK Top Bio-based Chemicals Opportunities. (2017).
115. Dutta, S., Wu, L. \& Mascal, M. Production of 5(chloromethyl)furan-2-carbonyl chloride and furan-2,5dicarbonyl chloride from biomass-derived 5-

(chloromethyl)furfural (CMF). Green Chem. 17, 3737-3739 (2015).

116. Zhou, C. et al. One-Step Approach to 2,5-Diformylfuran from Fructose over Molybdenum Oxides Supported on Carbon Spheres. ACS Sustain. Chem. Eng. 7, 315-323 (2019).

117. 27. Furan dialdehyde. Sugar Ser. 13, 210-213 (2000).

118. 20. Difurfural (5,5'-diformyl-2,2'-difuran). Sugar Ser. 13, 164-169 (2000).

119. Tachibana, Y., Hayashi, S. \& Kasuya, K. I. Biobased Poly(Schiff-Base) Composed of Bifurfural. ACS Omega 3, 5336-5345 (2018).

120. Masui, K., Ikegami, H. \& Mori, A. Palladium-Catalyzed C-H Homocoupling of Thiophenes: Facile Construction of Bithiophene Structure. J. Am. Chem. Soc. 126, 5074-5075 (2004).

121. Bloom, J. W. G. \& Wheeler, S. E. Benchmark torsional potentials of building blocks for conjugated materials: Bifuran, bithiophene, and biselenophene. J. Chem. Theory Comput. 10, 3647-3655 (2014).

122. Pyo, S. M. et al. Synthesis and characterization of a new blue-light-emitting polyimide. Macromolecules 31, 47774781 (1998).

123. Park, H. K. \& Ree, M. Blue-light-emitting polymers prepared from a new monomer having a well-defined conjugation length. Synth. Met. 117, 197-198 (2001).

124. Sonar, P., Foong, T. R. B., Singh, S. P., Li, Y. \& Dodabalapur, A. A furan-containing conjugated polymer for high mobility ambipolar organic thin film transistors. Chem. Commun. 48, 8383-8385 (2012).

125. Lee, S. M. et al. High-Performance Furan-Containing Conjugated Polymer for Environmentally Benign Solution Processing. ACS Appl. Mater. Interfaces 9, 15652-15661 (2017).

126. Woo, C. H., Beaujuge, P. M., Holcombe, T. W., Lee, O. P. \& Fréchet, J. M. J. Incorporation of furan into low band-gap polymers for efficient solar cells. J. Am. Chem. Soc. 132, 15547-15549 (2010).

127. Yiu, A. T. et al. Side-chain tunability of furan-containing low-band-gap polymers provides control of structural order in efficient solar cells. J. Am. Chem. Soc. 134, 21802185 (2012).

128. Ma, J., Du, Z., Xu, J., Chu, Q. \& Pang, Y. Efficient aerobic oxidation of 5-hydroxymethylfurfural to 2,5-diformylfuran, and synthesis of a fluorescent material. ChemSusChem 4, 51-54 (2011).

129. Hui, Z. \& Gandini, A. POLYMERIC SCHIFF BASES BEARING FURAN MOIETIES. Eur. Polym. J. 28, 1461-1469 (1992).

130. Xiang, T. et al. Schiff base polymers derived from 2,5diformylfuran. Polym. Int. 62, 1517-1523 (2013).

131. Antony-Babu, S. \& Goodfellow, M. Biosystematics of alkaliphilic streptomycetes isolated from seven locations across a beach and dune sand system. Antonie van Leeuwenhoek, Int. J. Gen. Mol. Microbiol. 94, 581-591 
(2008).

132. Suzuki, H., Ohnishi, Y., Furusho, Y., Sakuda, S. \& Horinouchi, S. Novel benzene ring biosynthesis from C3 and C4 primary metabolites by two enzymes. J. Biol. Chem. 281, 36944-36951 (2006).

133. Utley, J. H. P. \& Gruber, J. Electrochemical synthesis of poly(p-xylylenes) (PPXs) and poly(p-phenylenevinylenes) (PPVs) and the study of xylylene (quinodimethane) intermediates; an underrated approach. J. Mater. Chem. 12, 1613-1624 (2002).

134. Zare, E. N. et al. Progress in Conductive Polyaniline-Based Nanocomposites for Biomedical Applications: A Review. J. Med. Chem. (2019). doi:10.1021/acs.jmedchem.9b00803

135. Dan, L. I., Huang, J. \& Kaner, R. B. Polyaniline nanofibers: a unique polymer nanostructure for versatile applications. Acc. Chem. Res. 42, 135-145 (2009).

136. Huang, J. Syntheses and applications of conducting polymer polyaniline nanofibers. Pure Appl. Chem. 78, 1527 (2006).

137. Kan, K., Yamamoto, H., Kaneko, D., Tateyama, S. \& Kaneko, T. Novel $\pi$-conjugated bio-based polymer, poly(3-amino-4hydroxybenzoic acid), and its solvatochromism. Pure Appl. Chem. 86, 685-690 (2014).

138. Chen, C., Hong, X. \& Gao, Y. Electrosynthesis of poly(3amino-4-hydroxybenzoic acid) nanoparticles with electroactivity even in highly alkaline solutions. J. Appl. Polym. Sci. 132, 1-10 (2015).

139. Dan Tompkins. Body Armor Safety Initiative. NIJ Journal (2006).

140. Suzuki, M. (Kawasaki), Yokoyama, K. (Kawasaki) \& Kikuchu, Y. (Kawasaki). METHOD FOR PRODUCING AN AMINOHYDROXYBENZOIC ACID-TYPE COMPOUND (75). (2012).

141. Lee, J. K. et al. A new synthetic approach for polybenzoxazole and light-induced fluorescent patterning on its film. Macromolecules 38, 9427-9433 (2005).

142. Carayon, C. \& Fery-Forgues, S. 2-Phenylbenzoxazole derivatives: A family of robust emitters of solid-state fluorescence. Photochem. Photobiol. Sci. 16, 1020-1035 (2017).

143. Affeldt, R. F., De Amorim Borges, A. C., Russowsky, D. \& Severo Rodembusch, F. Synthesis and fluorescence properties of benzoxazole-1,4-dihydropyridine dyads achieved by a multicomponent reaction. New J. Chem. 38, 4607-4614 (2014).

144. Isikgor, F. H. \& Becer, C. R. Lignocellulosic Biomass: A Sustainable Platform for Production of Bio-Based Chemicals and Polymers. Polym. Chem. 34-50 (2015). doi:10.1016/B978-1-84569-741-9.50002-1

145. Llevot, A., Grau, E., Carlotti, S., Grelier, S. \& Cramail, H. Renewable (semi)aromatic polyesters from symmetrical vanillin-based dimers. Polym. Chem. 6, 6058-6066 (2015). 